Rodrigo Antonio Pereira Mauro

\title{
Dosimetria em Tomografia Computadorizada de Feixe Cônico Odontológica
}




\section{Rodrigo Antonio Pereira Mauro}

\section{Dosimetria em Tomografia Computadorizada de Feixe Cônico Odontológica}

Dissertação apresentada à Faculdade de Filosofia, Ciências e Letras de Ribeirão Preto da Universidade de São Paulo para obtenção do título de Mestre em Ciências. Área de concentração: Física Aplicada à Medicina e Biologia

Orientador: Prof. Dr. Alessandro Martins da Costa 
AUTORIZO A REPRODUÇÃO E DIVULGAÇÃO TOTAL OU PARCIAL DESTE TRABALHO, POR QUALQUER MEIO CONVENCIONAL OU ELETRÔNICO, PARA FINS DE ESTUDO E PESQUISA, DESDE QUE CITADA A FONTE.

FICHA CATALOGRÁFICA

Mauro, Rodrigo Antonio Pereira.

Dosimetria em Tomografia Computadoriza de Feixe Cônico Odontológica. Ribeirão Preto, 2017.

73 p.: il.; $30 \mathrm{~cm}$

Dissertação de Mestrado, apresentada à Faculdade de Filosofia, Ciências e Letras de Ribeirão Preto/USP. Área de concentração: Física Aplicada à Medicina e Biologia.

Orientador: Costa, Alessandro Martins da.

1. Radiodiagnóstico. 2. Dosimetria. 3. Tomografia Feixe Cônico Odontológica. 4. Radiologia Odontológica. 


\section{FOLHA DE APROVAÇÃO}

Rodrigo Antonio Pereira Mauro

Dosimetria em Tomografia Computadoriza de Feixe Cônico Odontológica.

Dissertação apresentada à Faculdade de Filosofia, Ciências e Letras de Ribeirão Preto da Universidade de São Paulo para obtenção do título de Mestre em Ciências. Área de concentração: Física Aplicada à Medicina e Biologia.

Aprovado em:

Banca Examinadora

Prof. Dr.

Instituição:

Assinatura:

Prof. Dr.

Instituição:

Assinatura:

Prof. Dr.

Instituição: Assinatura: 


\section{DEDICATÓRIA}

Dedicado a minha mãe, Sr. Edna, companheira inseparável nas horas fáceis e difíceis, meu exemplo de superação e dedicação, sempre em orações por proteção e vitória durante toda a minha caminhada. Ao meu pai e irmã, que estão sempre ao meu lado, torcendo e me apoiando nos trabalhos e épocas difíceis. Ao meu filho José Vitor, motivo de sempre correr atras da minha auto superação, me inspirando a cada fase da vida, me fazendo compreender o que é ser pai. A minha Namorada Natália, sempre se dedicando a me apoiar, me aconselhar, companheira pra toda a vida. Aos meu amigos, pessoas que sempre tem um tempinho pra trocar idéias e conhecimento. A minha grande amiga Daiane, parceira de questões acadêmicas, uma grande pessoa, sempre me aguentando com as piadas, e compartilhando dos meus sonhos. Ao Dr. Prof. Alessandro, que não é apenas orientador, mas sim, um grande amigo que quero levar pra toda a vida, sempre presente nas horas de discussão de idéias, desenvolvimento dos projetos, ajudando a conquistar meu título. 


\section{AGRADECIMENTOS}

Ao meu orientador, Prof. Dr. Alessandro Martins da Costa. Aos meu amigos, que colaboram para administração científica e psíquica. A todo o pessoal, docentes, funcionários e companheiros de laboratório, do Departamento de Física, Faculdade de Filosofia Ciências e Letras de Ribeirão Preto, Universidade de São Paulo. A Coordenação de Aperfeiçoamento de Pessoal de Nível Superior por financiar esta pesquisa, e também às clínicas particulares que cederam os tomógrafos odontológicos para avaliação. 
"Pouco conhecimento faz com que as pessoas se sintam orgulhosas. Muito conhecimento, que se sintam humildes. É assim que as espigas sem grãos erguem desdenhosamente a cabeça para o Céu, enquanto que as cheias as baixam para a terra, sua mãe." 


\section{Resumo}

Os objetivos deste trabalho foram caracterizar os Níveis de Referência de Radiodiagnóstico (NRR) para a tomografia computadorizada de feixe cônico odontológica (TCO) e as características de desempenho dos equipamentos como quilovoltaqgem de pico ( $k V p)$, rendimento, camada semi-redutora, etc., com o intuito de conhecer os aspectos dosimétricos mais práticos para aplicação de controle de qualidade na rotina clínica, os níveis de dose em que os pacientes estão expostos, identificar protocolos mais adequados, levando-se em consideração os princípios de radioproteção. A TCO tem se tornado ferramenta extremamente útil na utilização em procedimentos radiológicos na área odontológica, pois, a riqueza de informações que a imagem 3D trás para o planejamento cirúrgico ou em qualquer procedimento, minimiza as possibilidades de erro, possibilita diagnósticos mais confiáveis e esclarecedores, tendo influência direta no resultado final esperado pelo paciente. Por se tratar de uma técnica de imagem que utiliza radiação ionizante, deve-se ter uma atenção criteriosa voltada para os níveis de radiação em que tais equipamentos trabalham, além de implementar uma rotina de controle de qualidade, com o intuito de prezar pelos princípios de radioproteção dos indivíduos envolvidos no procedimento e a qualidade final da imagem. Atualmente, existem várias grandezas dosimétricas definidas para as diferentes modalidades de tomógrafos disponíveis, como por exemplo o Índice de Dose em Tomografia Computadorizada (CDTI), mundialmente utilizado como grandeza de referência utilizada em dosimetria de tomografia computadorizada; porém, tomando-se a forma geométrica do feixe utilizado em tomografia odontológica e ainda sua extensão, a definição de uma grandeza dosimétrica mais adequada se faz necessária, com o objetivo de evitar a subestimação dos níveis de dose. Diversos estudos aplicaram o Produto Kerma no Ar-Área, $P_{K A}$, para avaliação dosimétrica em radiografias intra-orais e panorâmicas, que também se tornou a grandeza utilizada para definir os níveis de dose de referência em radiodiagnóstico para estas categorias de procedimento radiológico; nessa linha de raciocínio, o $P_{K A}$ também tem sido utilizado como grandeza base em tomografia odontológica, uma vez que em sua metodologia de medida, todo o feixe é englobado pelo medidor, não depende da distância fonte-detector, além de ser sensível aos parâmetros de exposição. Diante de tais circunstâncias, o levantamento do $P_{K A}$ a partir dos equipamentos disponíveis na região de estudo, pode ser utilizado para estabelecimento dos níveis de dose de referência em diagnóstico odontológico. Os valores $P_{K A}$ obtidos para este estudo então em uma faixa entre $34,6 \mathrm{mGy} \cdot \mathrm{cm}^{2} \mathrm{e}$ $2901,6 \mathrm{mGy} \cdot \mathrm{cm}^{2}$, com valor médio de $980,7 \mathrm{mGy} \cdot \mathrm{cm}^{2}$. Os valores encontrados para NRR calculados a partir do $3^{\circ}$ quartil estão divididos em três classes referentes ao tamanho do campo de visão, onde para campos pequenos, médios e grandes os valores são $1241 \mathrm{mGy} \cdot \mathrm{cm}^{2}, 1521 \mathrm{mGy} \cdot \mathrm{cm}^{2}$ e $1408 \mathrm{mGy} \cdot \mathrm{cm}^{2}$ respectivamente, e $1446 \mathrm{mGy} \cdot \mathrm{cm}^{2}$ é o valor global. Os testes de controle de qualidade foram todos positivos, com uma atenção para o i-CAT FLX, que excedeu levemente o limite aceitável para a exatidão do kVp. Uma comparação entre $\mathrm{CTDI}_{100}$ e $\mathrm{CTDI}_{300}$, reportou que o $\mathrm{CTDI}_{300}$ é em 
média $49 \%$ maior em relação ao CTDI 100 . Os NRRs são representativos dos níveis de dose otimizados, e servem como base para adequação dos parâmetros de exposição diretamente relacionados a radioproteção dos pacientes. Os testes de controle de qualidade alertam para possíveis irregularidades no funcionamento do tomógrafo, e deve complementar obrigatoriamente a rotina dos procedimentos clínicos. 


\section{Lista de Figuras}

1 Ampola ou tubo de raios X. Adaptado de: Bushberg, J. T. \& Boone, J. M. (2011)(1) . . . . . . . . . . . . . . . . . . . . . p. 17

2 Distribuição de energia para um potencial gerador de $90 \mathrm{kV}$. Adaptado de: Bushberg, J. T. \& Boone, J. M. (2011)(1) _ . . . . . . . . . . p. p. 18

3 Espectro filtrado de radiação contínua e característica para um alvo de tungstênio e 90 kV. Adaptado de: Bushberg, J. T. \& Boone, J. M. (2011) (1) . . . . . . . . . . . . . . . . . . . . . p. 19

4 Curvas de atenuação versus espessura de alumínio para raios $X$ a partir de um alvo de tungstênio, filtrado por (A) $2 \mathrm{~mm} \mathrm{Al,} \mathrm{(B)0,15} \mathrm{mm}$ $\mathrm{Cu}+3,9 \mathrm{~mm} \mathrm{Al}$, e (C) $2 \mathrm{~mm} \mathrm{Sn}+0,5 \mathrm{~mm} \mathrm{Cu}+4 \mathrm{~mm}$ Al. Adaptado de: Attix, F. H. (2004)(2) . . . . . . . . . . . . . . . . . p. 20

5 Esquema da projeção do feixe paralelo que foi utilizada no primeiro tomógrafo. Adaptado de: Bushberg, J. T. \& Boone, J. M. (2011) (1) _ . p. 29

6 Ilustração dos deslocamentos realizado com uma $\mathrm{Cl}$ de $100 \mathrm{~mm}$ tipo lápis, para cobrir todo o feixe. Adaptado de: IAEA TechReport (3) . . . p. 49

$7 \quad$ Valores $\mathrm{P}_{\mathrm{KA}} \ldots \ldots \ldots \ldots \ldots \ldots \ldots \ldots \ldots \ldots \ldots \ldots$ 


\section{Lista de Tabelas}

1 Especificações técnicas referentes aos tomógrafos de feixe cônico odontológicos . . . . . . . . . . . . . . . . . p. 43

2 Resultados obtidos para CSR, rendimento, repetitividade e exatidão do $\mathrm{kVp}$ medidos para cada equipamento . . . . . . . . . . p.50

3 Produto Kerma no ar-área CRANEX 3D $\ldots \ldots \ldots \ldots \ldots \ldots$

4 Produto Kerma no ar-área Eagle 3D $\ldots \ldots \ldots \ldots \ldots \ldots$

5 Produto Kerma no ar-área i-CAT Classic . . . . . . . . . . . p. 52

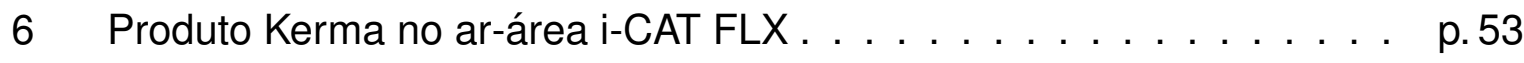

7 Produto Kerma no ar-área OP300 $\ldots \ldots \ldots \ldots \ldots \ldots \ldots$

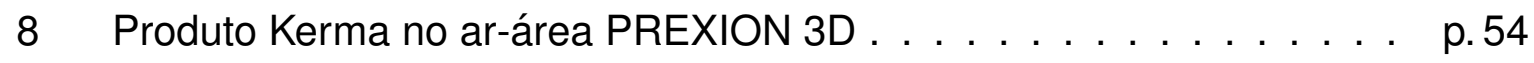

9 Produto Kerma no ar-área PAX Uni-3d . . . . . . . . . . . . . . p.54

10 Valores médios $P_{K A}$ para a divisão em classes de acordo com o tamanho do CDV . . . . . . . . . . . . . . . . p. 55

11 Cálculo dos quartis, representativos dos NRRs para três classes de CDVs, e uma classe global . . . . . . . . . . . . . p. 56

12 CTDI i-CAT Classic utilizando metodologia sugerida pela IAEA (3) . . p.57

13 Comparação $\mathrm{CTDI}_{300}$ em relação ao $\mathrm{CTDI}_{100}$ medidos para os equipamentos i-CAT Classic e Prexion 3D . . . . . . . . . . p. 58 


\section{Sumário}

1 Introdução $\quad$ p. 14

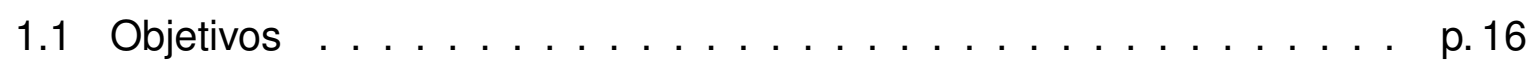

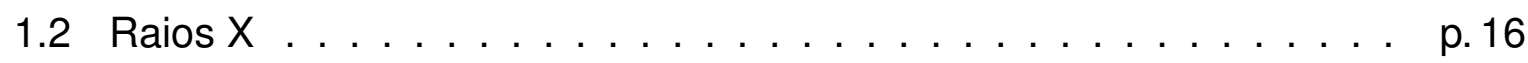

1.3 Produção de Raios $X \ldots \ldots \ldots \ldots \ldots \ldots \ldots$

1.3.1 Qualidade do Feixe de Raio X Diagnóstico $\ldots \ldots \ldots$ p. . . 18

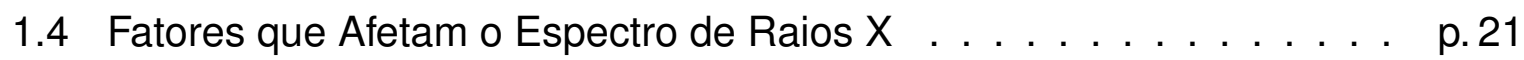

1.5 Grandezas Dosimétricas Básicas . . . . . . . . . . . . . . . p. 22

1.5 .1 Fluência $\ldots \ldots \ldots \ldots \ldots \ldots \ldots \ldots \ldots \ldots \ldots \ldots$

1.5.2 Fluência de Energia . . . . . . . . . . . . . . p.22

1.5 .3 Exposição . . . . . . . . . . . . . . . . . . p. 22

1.5 .4 Kerma . . . . . . . . . . . . . . . . p. 22

1.5 .5 Energia Cedida . . . . . . . . . . . . . . p. 23

1.5.6 Dose Absorvida . . . . . . . . . . . . . . . p. 23

1.6 Grandezas Dosimétricas para TC . . . . . . . . . . . . p. 23

1.6.1 Kerma no Ar Incidente . . . . . . . . . . . . . . . p. 23

1.6.2 Kerma no Ar na Superfície de Entrada . . . . . . . . . . . . p. 24

1.6.3 Produto Kerma no Ar-Área . . . . . . . . . . . . . . . . . p. 24

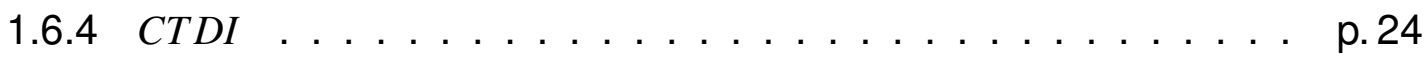

$1.6 .5 C^{C} D_{D I_{F A}} \ldots \ldots \ldots \ldots \ldots \ldots \ldots \ldots \ldots \ldots \ldots \ldots$

$1.6 .6 C T D I_{100} \ldots \ldots \ldots \ldots \ldots \ldots \ldots \ldots \ldots \ldots \ldots$

$1.6 .7 C T D I_{w} \ldots \ldots \ldots \ldots \ldots \ldots \ldots \ldots \ldots \ldots \ldots \ldots$ 
$1.6 .8 C^{C T D I_{v o l}} \ldots \ldots \ldots \ldots \ldots \ldots \ldots \ldots \ldots \ldots \ldots$

1.6.9 Produto Kerma Comprimento . . . . . . . . . . . . . . . p. 26

1.6.10 Limitações do CTDI . . . . . . . . . . . . . . . . . . . p. 26

1.6.11 Dose no Orgão em TC . . . . . . . . . . . . . . . . . . . . . p. 27

1.7 Grandezas Relacionadas a Efeitos Biológicos . . . . . . . . . . . p. 28

1.7.1 Equivalente de Dose . . . . . . . . . . . . . . . . . . . p. 28

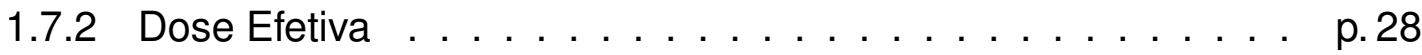

1.8 Tomografia Computadorizada . . . . . . . . . . . . . . . . . p. 28

1.9 Princípios de Funcionamento $\ldots \ldots \ldots \ldots$

1.10 Algorítmos de Reconstrução $\ldots \ldots \ldots \ldots$. . . . . . . . p.31

1.10 .1 Retroprojeção Simples . . . . . . . . . . . . . . . . . . . . . p.31

1.10.2 Retroprojeção Filtrada . . . . . . . . . . . . . . . . . . . p.31

1.10.3 Transformada de Fourier $\ldots \ldots \ldots \ldots \ldots$. . . . . . . . . .

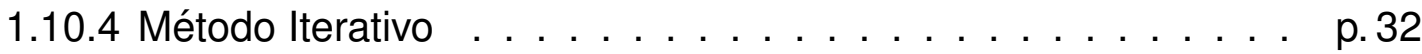

1.10 .5 Feixe Cônico . . . . . . . . . . . . . . . . . . . . . p.32

1.11 Modos de Aquisição . . . . . . . . . . . . . . . . . . . . . . p. p.33

1.11.1 Axial ou Sequencial . . . . . . . . . . . . . . . . . p.33

1.11.2 Helicoidal ou Espiral . . . . . . . . . . . . . . . . . . p. 33

1.11 .3 CT Cardíaca . . . . . . . . . . . . . . . . . . . . p. 34

1.11.4 Dupla Energia . . . . . . . . . . . . . . . . . . . p. 34

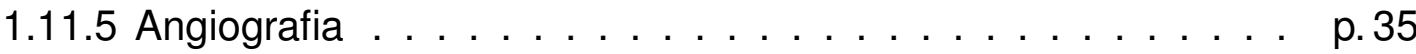

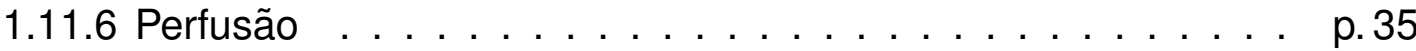

1.11 .7 Modulação de Dose . . . . . . . . . . . . . . . . . . . . . p.35

2 Revisão da Literatura $\quad$ p. 36

3 Materiais e Métodos $\quad$ p. 43 
3.1 Testes de Controle de Qualidade . . . . . . . . . . . . . . . . . . . p.44

3.2 Medição $\mathrm{P}_{\mathrm{KA}} \ldots \ldots \ldots \ldots \ldots \ldots \ldots$. . . . . . . . . . . . . . . . . . . . . .

3.3 Nível de Referência de Radiodiagnóstico $\ldots \ldots \ldots$. . . . . . . . . . . p. 46

3.4 Feixes Com Largura Nominal $>40 \mathrm{~mm} \ldots \ldots$. . . . . . . . . . . . p. 47

3.5 Medição No Ar Para Feixes $>60 \mathrm{~mm} \ldots \ldots$. . . . . . . . . . . 48

4 Resultados $\quad$ p. 50

4.1 Resultados $\mathrm{P}_{\mathrm{KA}} \ldots \ldots \ldots \ldots \ldots \ldots \ldots$. . . . . . . . . . . . . . . . . . . .

$4.23^{\circ}$ Quartil . . . . . . . . . . . . . . . . . . . . . p. 56

4.3 Resultados Feixes Com Largura Nominal $>40 \mathrm{~mm}$. . . . . . . . . . . p. 56

4.4 Resultados Feixe No $\mathrm{Ar}>60 \mathrm{~mm} \ldots \ldots \ldots$ p. . . . . . . . . . . . .

5 Discussão $\quad$ p.59

6 Conclusões $\quad$ p. 67

$\begin{array}{ll}\text { Referências } & \text { p. } 69\end{array}$ 


\section{Introdução}

As radiações ionizantes são agentes mutagênicos, de natureza danosa, que podem produzir malformações durante o desenvolvimento do embrião, reduzir a fertilidade tanto masculina quanto feminina, provocar a esterilidade dos órgãos reprodutores, incidir câncer, leucemia e levar a morte prematura tanto pelo detrimento de uma exposição fatal, quanto por efeitos estocásticos.

A utilização das radiações ionizantes, deve ser controlada, e otimizada a fim de se alcançar efeitos benéficos, quando seguramente utilizada. Devido aos seus efeitos deletérios, a utilização de radiação ionizante em instalações de saúde, são fortemente controladas, tanto no projeto de blindagem da instalação evitando que áreas de ocupação em torno da sala que abriga o aparelho emissor de radiação recebam níveis de radiação acima dos estabelecidos por normas de referência nacional, quanto na efetiva proteção radiológica dos indivíduos ocupacionalmente expostos, indivíduos do público e pacientes.

A tomografia computadorizada de feixe cônico odontológica é uma modalidade voltada à odontologia com a finalidade de auxiliar os cirurgiões dentistas em vários aspectos da área, como em ortodontia onde é possível verificar as angulações dentárias, análise cefalométrica 2D e 3D, avaliação das tábuas ósseas e sua modelação após movimentação ortodôntica, visualização da aderência de enxerto ósseo, reabsorção radicular, assimetrias faciais, mensurações do espaço aéreo. Na prototipagem é possível criar guia cirúrgico tanto para colocação de implantes como para o planejamento de cirurgia ortognática e próteses ortodônticas. Em implantodontia, é possível avaliar a qualidade, densidade, altura, e espessura óssea de locais em potencial para a colocação de implantes, avaliação da posição dos implantes em relação a estruturas adjacentes. Na cirurgia e diagnóstico buco-maxilo-facial é possível a reconstrução 3D do tecido ósseo, relação entre dente retido e os elemento adjacentes, análise de fratura facial e projeto balístico, localização de corpo estranho. Avaliação dos tecidos duros da articulação temporomandibular, dos espaços articulares e dos deslocamentos 
condilares. Em endodontia, é possível avaliar dilaceração radicular, fraturas radiculares, localização de perfurações radiculares. Em periodontia é possível avaliar a perda óssea alveolar, defeitos ósseos, lesão de furca (4-6).

A tomografia computadorizada odontológica (TCO) utilizada na prática de radiodiagnóstico odontológico é uma inovação na área; hoje em dia é reconhecido a grande facilidade na análise patológica trazida pela tomografia, porém, por se tratar de um equipamento gerador de radiação ionizante, os riscos associados não devem ser desconsiderados, e sim, uma especulação deve ser realizada sobre as características físicas e de funcionamento dos aparelhos atualmente no mercado. Os atributos para um protocolo de controle de qualidade desses equipamentos devem ser investigados, com o propósito de complemento dos estudos já realizados, em nível nacional e internacional, e estimular a revisão de regulamentos e normas nacionais que tratam do assunto de radioproteção e não garantem nenhum tipo de auxílio para tomografia computadorizada de feixe cônico odontológica (7).

Esta pesquisa tem em caráter, visar a radioproteção, tanto do paciente, quanto do pessoal ocupacionalmente exposto, uma vez que a utilização da tomografia computadorizada é uma das técnicas de imagem odontológica requerida em considerável quantidade. Devido às suas inúmeras aplicações, ocorre um uso exacerbado com respeito à justificação sobre o pedido do exame, onde outras modalidades seriam suficientes para avaliação patológica. Ambas as doses no paciente e no operador são potencialmente maiores que equipamentos de radiografia panorâmica e periapical, um cuidado maior é requerido em todos os aspectos do programa de controle de qualidade.

Faz-se necessária uma inspeção de tais equipamentos, para aferir se as características de funcionamento estão cumprindo com as normas nacionais, valores dosimetricos otimizados, que aumentam a radioproteção. A normatização da tomografia de feixe cônico odontológica na portaria 453 ainda não foi implementada, deixando os fabricantes ao bel-prazer de utilizar particulares metodologias de aquisição e posicionamento, como também de parâmetros dosimétricos; fatores que influenciam na qualidade da imagem e na dose entregue ao paciente. Também a necessidade de implementação dos assentamentos de doses para cada paciente, evitando assim que o pessoal técnico responsável pela realização do exame tome as devidas precauções durante a aquisição da imagem, precauções essas que podem ser simples na rotina clínica como um posicionamento correto do paciente, correta escolha do protocolo de 
aquisição, orientações ao paciente antes do procedimento, esclarecimento da justificativa; atos que estão englobados nos princípios de radioproteção, e que devem ser implementados na prática diária. O objetivo dos assentamentos de dose, ajudam para notificação, avaliação, e se necessário na investigação dos riscos ao paciente.

\subsection{Objetivos}

Caracterizar os Níveis de Referência de Radiodiagnóstico (NRR) para TCO, e as características de desempenho dos equipamentos como kVp, rendimento, camada semirredutora (CSR), com o objetivo de conhecer os aspéctos dosimétricos mais práticos para aplicação de controle de qualidade na rotina clínica, os níveis de dose em que os pacientes estão expostos, identificar protocolos mais adequados, levando-se em consideração os princípios de radioproteção.

\subsection{Raios X}

O raio $X$ é um tipo de radiação eletromagnética emitida por partículas carregadas. Quando estas partículas, geralmente elétrons, alternam entre os níveis de energia atômicos, emite-se um fóton de raio $X$ característico ou de fluorescência, ou quando os elétrons atingem o repouso pela frenagem no meio, devido às forças Coulombianas, emite-se um fóton de raio $\mathrm{X}$ contínuo ou de Bremsstrahlung (radiação de frenagem). O ICRU 1971 (8) faz uma diferenciação entre as formas de interação das radiações ionizantes por partículas carregadas e não carregadas. No caso dos raios $X$, partículas não carregadas, é um tipo de radiação indiretamente ionizante que interagem com partículas carregadas presentes no meio, transferindo parcial ou totalmente a sua energia. As partículas carregadas, agora com energia cinética adquirida do fóton, faz seu caminho de ionização até o repouso, o processo ocorre em dois passos (2).

\subsection{Produção de Raios X}

Na Figura 1 está esquematizado de maneira bem simples uma ampola de raios $\mathrm{X}$, onde ocorre todo o processo de produção. Os raios $X$ são criados a partir da conversão de energia cinética dos elétrons em radiação eletromagnética, quando são desacelerados por interação com o meio. Os elétrons são liberados por efeito termoiônico 


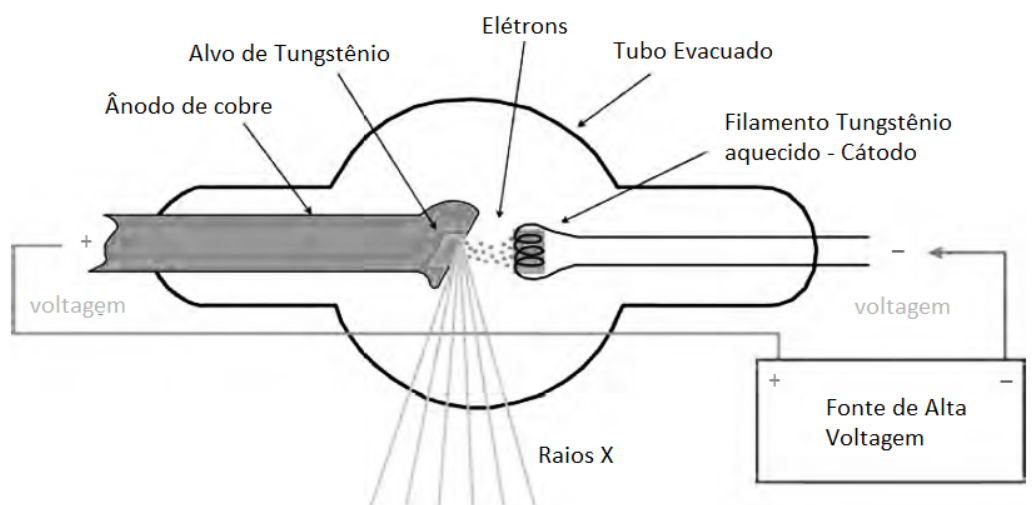

Figura 1: Ampola ou tubo de raios X. Adaptado de: Bushberg, J. T. \& Boone, J. M. $(2011)(1)$

no cátodo, onde há um filamento aquecido, e um copo focalizador responsável pela colimação dessa corrente de elétrons no alvo ou ânodo. Uma diferença de potencial é aplicada entre os eletrodos (ânodo e cátodo), o que torna possível a aceleração dos elétrons a partir do cátodo para o ânodo. O ânodo se encontra em um potencial positivo em relação ao cátodo, assim o ânodo atrai os elétrons e o cátodo repele elétrons; um potencial na faixa de 20 a $150 \mathrm{kV}$ é aplicado entre os eletrodos, e a energia adiquirida pelos elétrons é a sua carga multiplicado pelo potencial, onde a unidade de energia cinética para os elétrons é dada em elétronVolt (eV) equivalente a $1,602^{-19} \mathrm{~J}$.

A interação do elétron acelerado com o alvo é colisional, a energia cinética do elétron é convertida em radição eletromagnética, os raios $X$, e também em calor, que provoca o aquecimento do ânodo no local da colisão, necessitando as vezes de um sistema de refrigeração. Devido a força Coulombiana ser proporcional ao inverso do quadrado da distância entre as cargas, a energia dos raios $X$ não assume valor exato, a interação do elétron com o núcleo será forte se a direção do elétron se aproximar muito ou incidir diretamento no núcleo, fenômeno raro de acontecer, e o elétron entrega quase ou toda sua energia ao fóton de Bremsstrahlung emitido. Se o elétron passar longe do núcleo, a interação é fraca, e o elétron transfere parte da sua energia ao fóton. Esse comportamento caracteriza um espectro de energia contínuo, onde as energias dos fótons vão de quase zero, até a energia inicial antes da colisão do elétron. A Figura 2 exemplifica o espectro de raios $X$ contínuo. Os fatores pricipais que afetam a produção de raios $X$ são o número atômico do material alvo, e a energia cinética que o elétron alcança quando é acelerado.

Os átomos possuem núcleo e eletrosfera, esta última é onde todos os elétrons do átomo estão organizados em níveis de energia discretos que são chamados também 


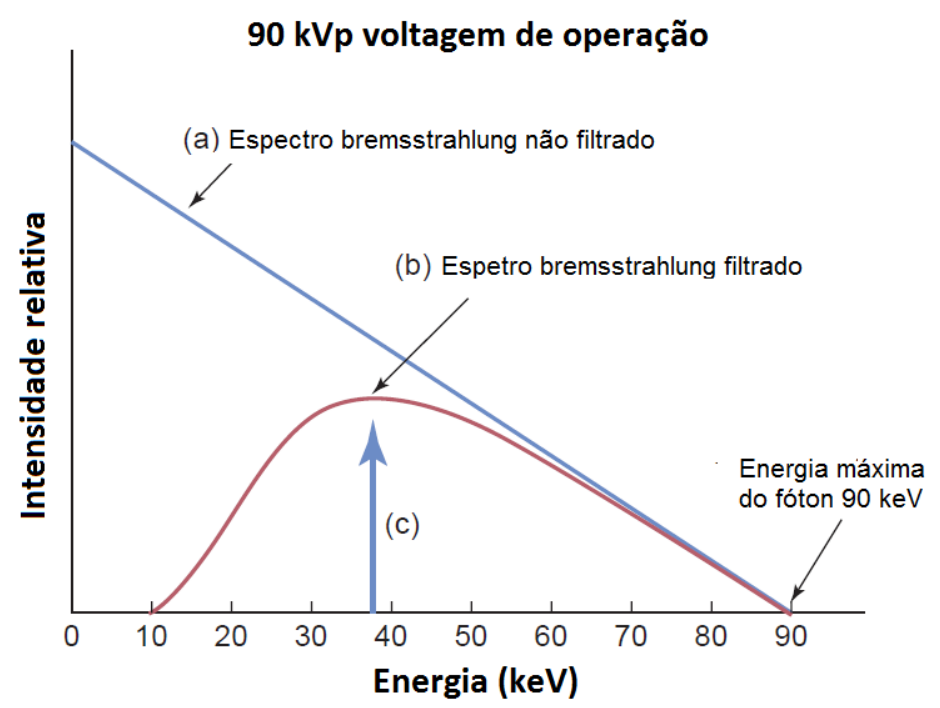

Figura 2: Distribuição de energia para um potencial gerador de $90 \mathrm{kV}$. Adaptado de: Bushberg, J. T. \& Boone, J. M. (2011)(1)

de camadas. Cada elétron em uma camada, possui uma energia de ligação que é característica de cada camada e do elemento em questão, por exemplo, elétrons presentes na camada $K$ são os mais difíceis de arrancar devido a sua energia de ligação maior, em relação a camadas mais externas, como $L, M, N$, etc. Além do espectro contínuo, tem-se o espectro de energia característico, que ocorre quando a energia dos elétrons acelerados supera a energia de ligação de um elétron presente no material alvo, ionizando o átomo, onde cria-se uma vacância na camada, assim, essa vacância precisa ser preenchida, então um elétron de uma camada mais externa transita para a camada mais interna, preenchendo a vacância, quando essa transição ocorre, há a emissão de um fóton de energia definida ou característica, a diferença da energia de ligação entre as camadas de transição é o valor de energia do fóton emitido, que será sempre a mesma energia, considerando o mesmo tipo de transição. Pode haver vários tipos de transições entre camadas adjacentes ou não, e em cada tipo de transição, uma energia bem definida. Observe a Figura 3 que exemplifica picos de energia bem definida, em meio do espectro contínuo. A produção de energia característica depende da energia cinética dos elétrons, e do material alvo (1).

\subsubsection{Qualidade do Feixe de Raio X Diagnóstico}

A qualidade de um feixe de raios $X$ é uma característica energética intrínseca de cada feixe, e varia com a energia dos elétrons, tipo de material alvo e filtração. Ou 


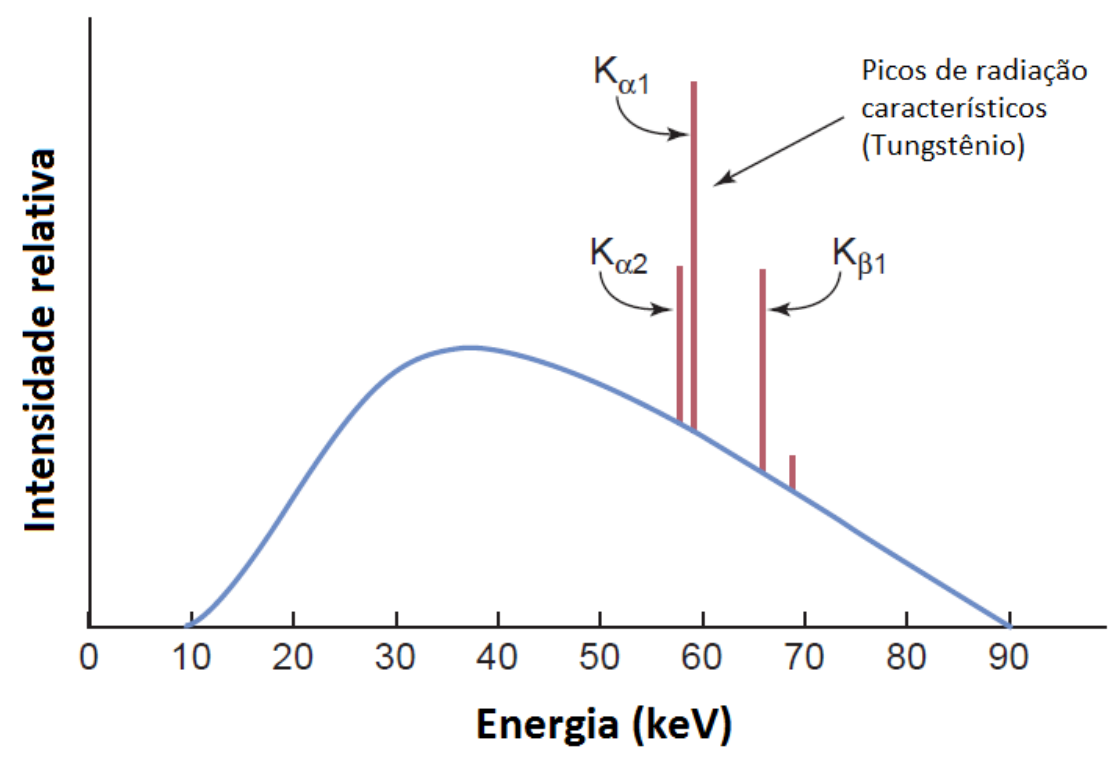

Figura 3: Espectro filtrado de radiação contínua e característica para um alvo de tungstênio e 90 kV. Adaptado de: Bushberg, J. T. \& Boone, J. M. (2011) (1)

espectro de energia, ou a característica de atenuação do feixe em um meio, podem especificar a qualidade do feixe.

Cada espectro está unicamente relacionado a uma curva de atenuação dada em um meio. Então é necessário padronizar alguns dados para que o fator de qualidade do feixe, seja reprodutível em qualquer lugar. Geralmente para o meio atenuante usase alumínio ou cobre, sendo o Al o principal para energia inicial do fóton menor que 120 $\mathrm{keV}$, e Cu para energias menores que $500 \mathrm{keV}$. Usar uma geometria de feixe estreita, o que minimiza os fótons de raios $\mathrm{X}$ expalhados pelo atenuador alcançarem o detector, e este, deve ser equivalente em ar, ser reprodutível na resposta e independente da energia. Em um determinado feixe de radiação e meio atenuante, a forma da curva de atenuação também pode ser dada pela dependência energética do detector.

A figura 4 mostra curvas de atenuação para um espectro com diferentes espessuras e materiais de filtros, e ainda a atenuação para um feixe monoenergético de $100 \mathrm{keV}$. Observando a curva $A$, pode-se conluir que o feixe possui um espectro largo em energias, e mais suave. Conforme a filtração fica maior, aumenta-se o endurecimento do feixe, e o estreitamento do espectro torna-se evidente, ou seja, a energia efetiva do feixe ( termo utilizado para representar a energia de um feixe polienergético a partir de um feixe monoenergético, calculada através da $\mathrm{CSR}_{1}$ que é a espessura necessária pra se reduzir a intensidade do feixe poli e monoenergético pela metade ) torna-se mais alta, pela redução dos fótons de baixa energia, deslocando o espectro 


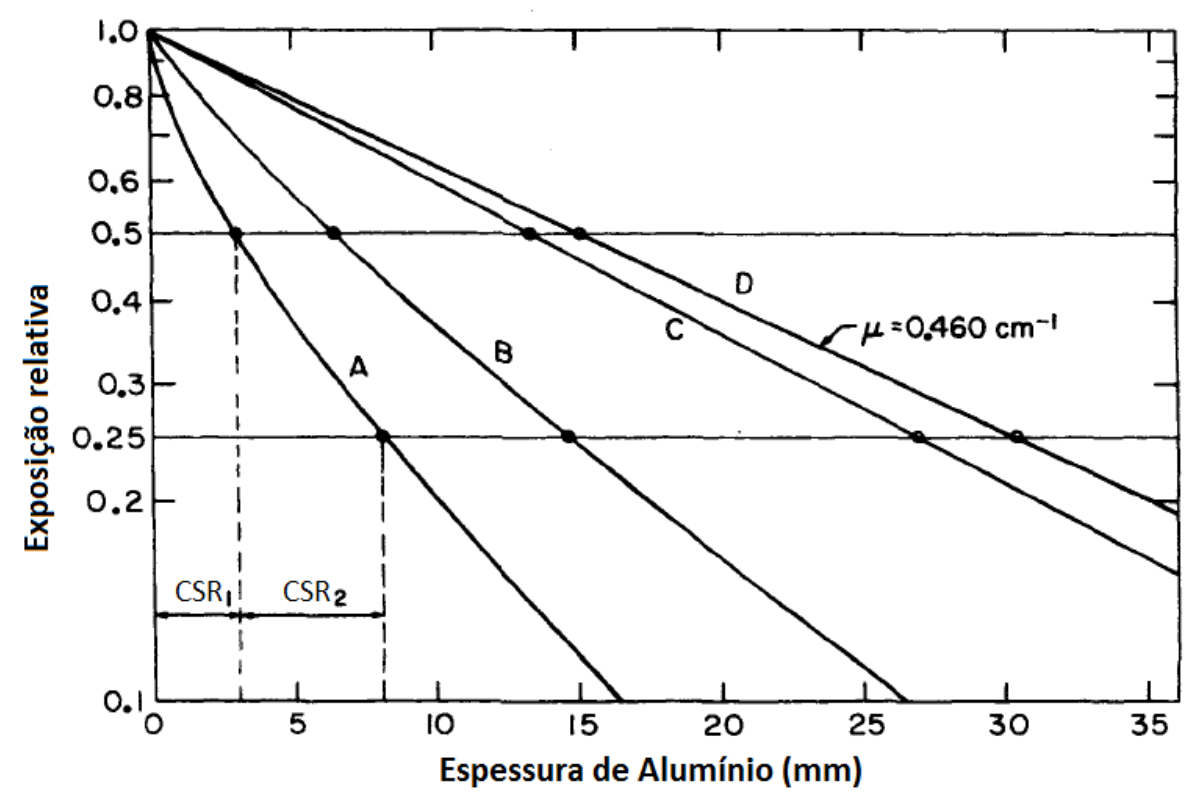

Figura 4: Curvas de atenuação versus espessura de alumínio para raios $X$ a partir de um alvo de tungstênio, filtrado por (A) $2 \mathrm{~mm} \mathrm{Al},(B) 0,15 \mathrm{~mm} \mathrm{Cu}+3,9 \mathrm{~mm} \mathrm{Al}$, e (C) 2 $\mathrm{mm} \mathrm{Sn}+0,5 \mathrm{~mm} \mathrm{Cu}+4 \mathrm{~mm}$ Al. Adaptado de: Attix, F. H. (2004)(2)

para energias maiores. Para espessuras grandes de filtros, a curva da resposta relativa se aproxima da curva para o feixe monoenergético, como se oberva pela curva C.

Essas curvas de atenuação podem ser caracterizadas pela primeira e segunda camada semirredutora , $\mathrm{CSR}_{1}$ e $\mathrm{CSR}_{2}$, onde a $\mathrm{CSR}_{1}$ é a espessura de material atenuante necessária para reduzir à metade a fluência de fótons incidente, e a $\mathrm{CSR}_{2}$ é a espessura para se reduzir à metade a fluência de fótons que atravessa a $\operatorname{CSR}_{1}$. Isso está exemplificado na figura 4 para a curva $A$, onde a espessura $\mathrm{CSR}_{1}$ corresponde a 0,5 e a $\mathrm{CSR}_{2}$ corresponde a 0,25 da exposição relativa inicial.

Um outro fator importante relacionado à largura do espectro é o coeficiente de homogeneidade, que é definido pela razãp da $\mathrm{CSR}_{1}$ pela $\mathrm{CSR}_{2}$. Quanto mais próximo de 1 , significa que o feixe é mais homogêneo ou quase monoenergético; se seu valor for 1 , o feixe é monoenergético e a curva de atenuação é exponencial; se próximo de 0 , indica que o espectro do feixe é heterogêneo e possui uma ampla distribuição em enegia. 


\subsection{Fatores que Afetam o Espectro de Raios X}

A produção de raios $X$ pode ser caracterizada a partir da qualidade do feixe, quantidade e exposição. A qualidade está definida na seção anterior. A quantidade refe-se ao número de fótons de raios $X$ que compõe o feixe. A exposição é proporcional a fluência do feixe.

Material do Alvo ou Ânodo: tem influência direta na eficiência de produção de radiação por Bremsstrahlung, os elétrons tendem a interagir mais com elementos de maior número atômico. Também tem influência sobre a produção e energia dos fótons característicos, que é dependente do elemento alvo utilizado.

Voltagem do Tubo (kV): determina a energia máxima do espectro de fótons, afeta a qualidade do feixe, influencia diretamente a eficiência de produção de raios $X$. A unidade de medida para voltagem do tubo é dada em Volts $(V)$ e é da ordem de $10^{3}$, assim para se referir a está grandeza fala-se diretamente em kV. Uma variação desta unidade, é o kVp (Quilovoltagem de Pico) que representa a maior voltagem aplicada entre o cátodo e o ânodo.

Corrente do Tubo (mA): está diretamente relacionada com a quantidade de fótons que é produzido no tubo, já que representa o número de elétrons que flui do cátodo para o ânodo. A quantidade também é proporcional ao tempo de que dura a produção de raios $X$. A exposição é proporcional ao $\mathrm{mAs}$, que é o produto da corrente pelo tempo de produção.

Filtração do Feixe: modifica a quantidade e qualidade do feixe. No espectro, quanto maior a filtração, menor é a área sob a curva espectral, e mais deslocada para a direita que significa uma energia efetiva maior.

Protocolo de aquisição: é o conjunto de informações referentes aos fatores que afetam o espectro de raios $X$, que são combinados para se adequar a uma determinada técnica de imagem e otimizar a exposição e qualidade de imagem, visando em todos os sentidos a radioproteção. 


\subsection{Grandezas Dosimétricas Básicas}

\subsubsection{Fluência}

É a quantidade de fótons dN que atravessam uma esfera de área de seção transversal da, como se segue:

$$
\Phi=\frac{d N}{d a}
$$

Unidades em $\mathrm{m}^{-2}(9)$.

\subsubsection{Fluência de Energia}

É a quantidade de energia dR que atravessam uma esfera de área de seção transversal da, como se segue:

$$
\Psi=\frac{d R}{d a}
$$

Unidades em $\mathrm{J} \cdot \mathrm{m}^{-2}$ onde $\mathrm{J}$ é a unidade de energia em Joule (9).

\subsubsection{Exposição}

A exposição $X$, é o valor absoluto da carga de íons de um sinal $d Q$, que são produzidos no ar considerando que todos os elétrons criados por fótons e liberados no ar de massa dm são completamente freados.

$$
X=\frac{d Q}{d m}
$$

Unidades em $\mathrm{C} / \mathrm{kg}$, onde $\mathrm{C}$ é a unidade de carga elétrica Coulomb.

\subsubsection{Kerma}

O Kerma (K) é a soma da energia cinética inicial de todas as particulas carregadas liberadas por particulas não carregadas dividida por um elemento de massa dm de material, como se segue:

$$
K=\frac{d E_{t r}}{d m}
$$

Unidades em J/kg (9). 


\subsubsection{Energia Cedida}

É a energia média $\bar{\varepsilon}$ entregue para a matéria, em um dado volume que é igual a energia radiante $R_{\text {in }}$ de todas a partículas carregadas e não carregadas que entram num volume, menos a energia radiante $R_{\text {out }}$ de todas partículas carregadas e não carregadas que deixam o volume, mais a soma $\Sigma Q$, de todas as conversões de massa em energia ou energia em massa das partículas que ocorrerem dentro do volume, assim:

$$
\bar{\varepsilon}=R_{\text {in }}+R_{\text {out }}+\sum Q
$$

Unidades em J (9).

\subsubsection{Dose Absorvida}

É a energia entregue $\bar{\varepsilon}$ dividida pela massa $\mathrm{dm}$.

$$
D=\frac{\bar{\varepsilon}}{d m}
$$

Unidades em J/kg, também chamado de Gray (Gy). Para um dado material, a dose absorvida e o Kerma são iguais quando há equilíbrio de partículas carregadas (9).

\subsection{Grandezas Dosimétricas para TC}

A dosimetria para TC é uma reunião de técnicas, métodos e diferentes instrumentos com o objetivo de avaliar ou estimar a dose entregue ao paciente que é submetido ao procedimento, umas vez que esta medida não só está relacionada ao controle de qualidade da máquina em si, mas também da proteção radiológica que o paciente deve receber, é o que fundamenta o princípio Alara.

\subsubsection{Kerma no Ar Incidente}

É o Kerma no ar $\left(\mathrm{K}_{\mathrm{i}}\right)$, no eixo central do feixe indicente a uma distância foco superfície da pele. Não considera-se a radiação retro espalhada, apenas a primária, pois a medida é realizada sem objeto simulador no feixe. Unidade de medida é o $\mathrm{J} / \mathrm{kg}$ ou Gy (9). 


\subsubsection{Kerma no Ar na Superfície de Entrada}

É o Kerma no ar $\left(K_{e}\right)$, no eixo central do feixe incidente medido na posição da superfície do paciente ou objeto simulador. Considera-se a radiação indicente e a retroespalhada pelo objeto simulador. Unidade de medida é o J/kg ou Gy (9). Existe uma correlação entre $\mathrm{K}_{\mathrm{e}}$ e $\mathrm{K}_{\mathrm{i}}$ como:

$$
K_{e}=K_{i} \cdot B
$$

em que B é o fator de retroespalhamento para uma dada energia em questão.

\subsubsection{Produto Kerma no Ar-Área}

É a integral do kerma no ar sobre a área $\left(P_{K A}\right)$ do feixe de raios $X$ no plano perpendicular ao eixo central do feixe.

$$
P_{K A}=\int_{A} K(x, y) d x d y
$$

Unidades em $\mathrm{J} \cdot \mathrm{kg}^{-1} \cdot \mathrm{m}^{2}$ ou $\mathrm{Gy} \cdot \mathrm{m}^{2}(9)$.

O $P_{K A}$ possui a característica de não variar com a distância fonte detector, deve ser medido distante do paciente ou detector, para evitar a radiação retroespalhada. $O$ $\mathrm{P}_{\mathrm{KA}}$ tem sido explorado como parâmetro dosimetrico de radiografias 2D e TC odontológicas.

\subsubsection{CTDI}

O CTDI (Computed Tomography Dose Index), é a dose média representada no eixo z, definida para apenas uma rotação do tubo de raios X. É calculada a partir da integral da dose absorvida dividido pela largura nominal do feixe colimado. Os limites de integração foram definidos entre os infinitos negativo e positivo, (10).

$$
C T D I=\frac{1}{N \cdot T} \int_{-\infty}^{\infty} D(z) d z
$$

Foi originalmente definido como um índice e não como um método direto de avaliação dosimetrica do paciente (1). 


\subsection{5 $C T D I_{F D A}$}

Os limites de integração dependem da largura nominal do feixe de radiação e do material espalhador, assim a FDA (Food and Drugs Association) definiu como padrão um limite de integração de $\pm 7 \mathrm{~T}$, onde $\mathrm{T}$ representa a largura nominal da fatia.

$$
C T D I=\frac{1}{N \cdot T} \int_{-7}^{7} D(z) d z
$$

\subsection{6 $C T D I_{100}$}

É a dose média representada no eixo $z$ ao logo de um comprimento de integração de $100 \mathrm{~mm}$ durante apenas uma rotação do tubo de raios $\mathrm{X}$, o que garante evitar a superestimação da dose para fatias mais estreitas $(<3 \mathrm{~mm})$.

$$
C T D I_{100}=\frac{1}{N \cdot T} \int_{-50}^{50} D(z) d z
$$

Aqui a radiação primaria e espalhada são levadas em consideração e a largura na fatia é definida por N.T $(1,11)$ É utilizado uma camara de ionização tipo lápis com comprimento de $100 \mathrm{~mm}$.

\subsection{7 $C T D I_{w}$}

Existe uma variação do valor CTDI medido com relação ao tamanho do campo de visão (CDV). O CTDI ${ }_{w}$ leva em consideração a média da dose periférica ponderada por um fator de $2 / 3$ somada a média da dose central ponderada por um fator de $1 / 3$, isso remete a estudos que demostraram que a dose na superfície do CDV é duas vezes maior que a dose no centro do CDV (12).

$$
C T D I_{W}=\frac{1}{3} C T D I_{100, \text { centro }}+\frac{2}{3} C T D I_{100, \text { borda }}
$$

Este índice de dose é medido em objeto simualdor (PMMA) e toma em conta a variação de dose sobre a seção transversal ou plano axial do objeto simulador, e o perfil de dose ao longo do eixo z, limitado a um intervalo de integração de $100 \mathrm{~mm}$, restringida pelo comprimento da câmara tipo lapis $(11,13)$. 


\subsection{8 $C T D I_{v o l}$}

Para protocolos especificos de aquisição, onde ocorre a aquisição de vários cortes axiais sucessivos, pode ocorrer a interposição do feixe de raios $X$ entre cada corte ou aparecer intervalos de ar onde o feixe de raios $X$ não incide, assim um descritor de dose que caracteriza estas duas situações diferentes é definido e apresentado a seguir:

$$
C T D I_{v o l}=\frac{N \cdot T}{I} \cdot C T D I_{w}
$$

O fator que define a sobreposição ou o intervalo de ar entre aquisições sequenciais é chamado de pitch (passo), definido como:

$$
\text { pitch }=\frac{I}{N \cdot T}
$$

onde I é o incremento da mesa durante uma única rotação. E N.T é a largura nominal do feixe, onde $\mathrm{N}$ é o número de linhas de detectores e $\mathrm{T}$ é a largura do elemento sensor. O intervalo de integração é de $100 \mathrm{~mm}$ (11).

\subsubsection{Produto Kerma Comprimento}

O $\mathrm{P}_{\mathrm{KL}}$ (Product Kerma Length) representa a dose média no volume para um dado protocolo utilizado, onde a integral da dose é feita por toda a extensão do volume escaneado:

$$
P_{K L}=C T D I_{v o l} \cdot L
$$

L é o comprimento escaneado.

O $\mathrm{P}_{\mathrm{KL}}$ representa a energia total absorvida e o potencial efeito biológico. Para os

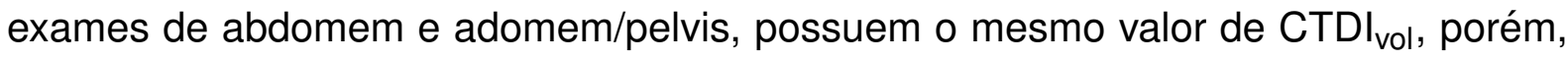
quando compara-se os valores de $\mathrm{P}_{\mathrm{KL}}$ respectivos, abdomem/pelvis terá o maior $\mathrm{P}_{\mathrm{KL}}$, pois o comprimento de integração da dose é maior (11). Existe uma proporcionalidade direta entre dose e comprimento escaneado, o que caracteriza valores de $\mathrm{P}_{\mathrm{KL}}$ característicos para cada tipo de aquisição e comprimento escaneado.

\subsubsection{Limitações do CTDI}

O CTDI possui algumas limitações devido ao comprimento escaneado que é definido e utilizado. Para escanear um comprimento de $250 \mathrm{~mm}$ de um corpo, a dose 
acumulada é próxima à dose de equilíbrio limite, onde a consideração da contribuição da cauda de radiação espalhada é máxima. O CTDI $_{100}$ subestima a dose CTDI no centro por um fator de 0,6 e na periferia por um fator de 0,8 e o $P_{K L}$ por um fator de 0,7 para todos os comprimentos. Um objeto simulador de $400 \mathrm{~mm}$ deve ser utilizado para medir a dose de equilíbrio (14).

\subsubsection{Dose no Orgão em TC}

As estimativas de dose no orgão pode se dar de várias formas, a partir de simulação computacional, índices de dose como o $\mathrm{CTDI}_{\mathrm{vol}, \mathrm{w}, 100, \ldots}$, medidas através de dosimetro termoluminescente posicionados em regiões específicas num objeto simulador antropomórfico. Esses métodos tentam fornecer corretamente a dose que o paciente recebe, trazendo parâmetros de informação para comparação entre tomógrafos e protocólos diferentes. O método de simulação Monte Carlo, é atualmente o mais utilizado para derivar os fatores de conversão para dose no orgão, e utiliza todos os parâmetros para simular uma situação real como: parâmetros de exposição de máquina (mAs, kVp, filtros, CSR), coordenadas de posicionamento do paciente, comprimento de digitalização, distância fonte isocentro, tamanho do campo, espectro de raios $X$, etc. Existem vários pacotes de simulação atualmente disponíveis no mercado como : CT-Expo V 2.1; ImpactDose; CTDosimetry.xls v1.0; P-Dose; entre outros.

A dosimetria no orgão geralmente é calculada usando tabelas de conversão, assim como para radiografias. Para estas considera-se o Kerma no Ar na Superfície de Entrada $\left(\mathrm{K}_{\mathrm{e}}\right)$ para a construção das tabelas, grandeza que não pode ser aplicada para tomografia, pois a distância fonte superfície varia durante a rotação do tubo de raios $X$ em volta do paciente, resultando em valores enganosos para o fator de correção; para corrigir essa limitação, faz-se a dosimetria no isocentro de rotação, onde a distância fonte isocentro permanece constante. A dose no orgão, é calculada levando-se em consideração que todo o orgão foi irradiado pelo feixe (3). A dose média absorvida em um tecido específico ou orgão é representada pelo símbolo $D_{\text {T }}$ definido no ICRU 51 (15). É a energia cedida para o tecido ou orgão dividida pela massa $m_{T}$ do orgão ou tecido, como a seguir:

$$
D_{T}=\frac{\overline{\varepsilon_{T}}}{m_{T}}
$$

A dose média absorvida no orgão também é chamada de dose no orgão (9). 


\subsection{Grandezas Relacionadas a Efeitos Biológicos}

\subsubsection{Equivalente de Dose}

A dose equivalente $\left(\mathrm{H}_{\mathrm{T}}\right)$ é definida pla ICRP 60 e ICRU 51, onde para um tipo de radiação $R$, ela é o produto do fator de peso para esta radiação $w_{R}$, e a dose no órgão $\mathrm{D}_{\mathrm{T}}$, assim:

$$
H_{T}=w_{R} \cdot D_{T}
$$

O fator de peso da radiação permite diferenciar o efeito biologico relativo causada pelo tipo de radiação incidente $R$ em baixas doses no orgão ou tecido $T$. Para a energia de radiodiagnóstico, a fator de pesó é unitário $(9,15)$.

\subsubsection{Dose Efetiva}

A dose efetiva (E), definida pela ICRP 60 (16) e ICRU 51 (15), é a soma da dose equivalente para todos os orgãos e tecidos do corpo, multiplicado pelo fator de peso para cada tipo de tecido ou orgão $\mathbf{w}_{\mathrm{T}}$, assim

$$
E=\sum_{T} w_{T} H_{T}
$$

O fator de peso $\mathrm{w}_{\mathrm{T}}$ representa a contribuição relativa do detrimento originário a partir de efeitos estocásticos para irradiação uniforme de corpo todo. Unidades em $\mathrm{J} / \mathrm{kg}$ ou geralmente em sievert (Sv). A soma do fator de peso para todos os orgãos do corpo é unitária (9).

\subsection{Tomografia Computadorizada}

O físico Allan Cormack desenvolveu uma teoria de recostrução que acreditava ser possível mostrar diferenças na absorção entre estruturas como por exemplo, tecido mole. Seu estudo se baseou em calcular a distribuição de absorção de radiação no corpo humano através de medidas de transmissão da radiação, que foi publicada em dois artigos no Journal of Applied Physics em 1963 e 1964. Trabalhando independentemente, o engenheiro Godfrey Hounsfield construiu a primeira máquina de tomografia, instalada em 1971, que foi descrita no British Journal of Radiology em 1973. Em 1974, a Siemens tornou-se o primeiro produtor padrão para TC de cabeça. Am- 
bos compartilharam o prêmio nobel de medicina em 1979. Hounsfield ficou conhecido como o pai da tomografia computadorizada $(17,18)$.

\subsection{Princípios de Funcionamento}

O princípio da imagem TC é a transmisão dos fótons de raios $X$ através de um corpo, e a detecção da intensidade desses fótons. Um tubo de raios $X$ é responsável pela produção dos fótons incidentes no objeto, e um arranjo de detectores são responsáveis pela captação desses fótons após a transmissão. O tubo e os detectores giram de maneira simultânea e diametralmente opostos. A figura 5 ilustra o primeiro sistema de transmisão, onde a geometria do feixe é paralela pelo fato da fonte e o detector se deslocarem para irradiar uma determinada região, até a cobertura completa do corpo, e isso é realizado ao longo dos $360^{\circ}$ com intervalos angulares pré definidos. Essa geometria é chamada projeção do feixe paralelo (1). O princípio de formação

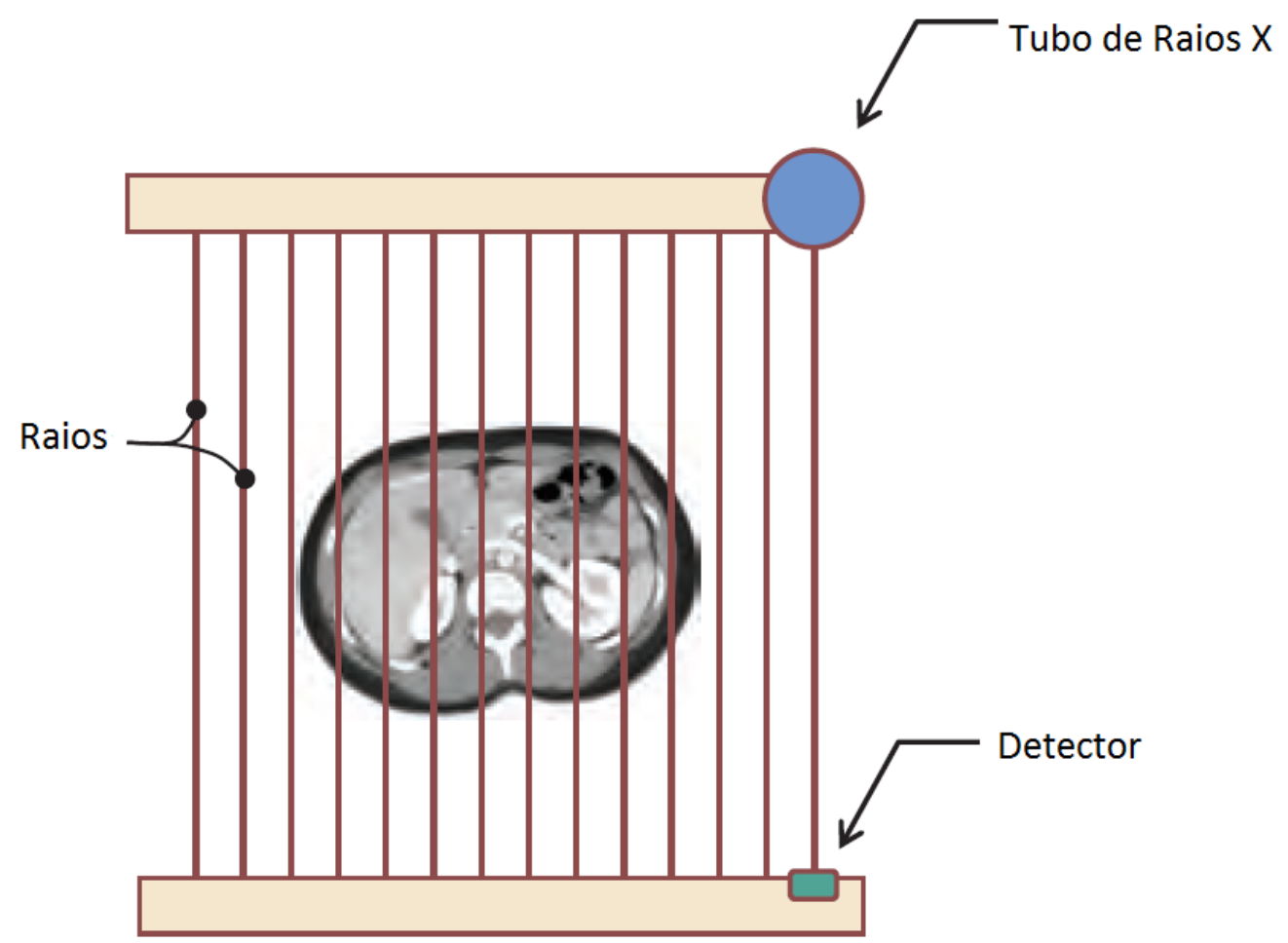

Figura 5: Esquema da projeção do feixe paralelo que foi utilizada no primeiro tomógrafo. Adaptado de: Bushberg, J. T. \& Boone, J. M. (2011) (1)

da imagem tomográfica vem dos primórdios da radiografia $2 \mathrm{D}$ convencional, onde a diferença de densidade entre as estruturas internas do corpo atenuam menos ou mais o feixe de raios $X$, assim criando o contraste na imagem, que permite delimitar e di- 
ferenciar estruturas anatômicas. Na tomografia, um detector mede a intensidade do feixe de raios $X$ ao passar através do objeto, considerando o meio atenuante um meio homogêneo, e a energia do feixe quase monoenergética, a relação entre as intensidades inicial e final com o meio atenuante, se dá da seguinte forma:

$$
I=I_{0} e^{-\mu x}
$$

Se o meio possuir, por exemplo, densidades diferentes com respectivos coeficientes de atenuação $\mu_{1}$ e $\mu_{2}$ com espessuras de atenuação $x_{1}$ e $x_{2}$ a equação fica:

$$
I=I_{0} e^{-\left(\mu_{1} x_{1}+\mu_{2} x_{2}\right)}
$$

E ainda, se existe um corpo com várias regiões com densidades diferentes e seus respectivos coeficientes de atenuação e espessuras, pode-se determinar uma equação geral para representar a transmissão do feixe:

$$
I=I_{0} e^{-\sum_{i=1}^{n} \mu_{i} x_{i}}
$$

Aqui, a variável de interesse é o coeficiente de atenuação, que pode ser obtido aplicando logarítmo na equação anterior:

$$
\ln \left(\frac{I_{0}}{I}\right)=\sum_{i=1}^{n} \mu_{i} x_{i}
$$

Não é possível determinar $\mu$ apenas com uma transmissão, pois, essa variável além de ser bastante discrepante entre as regiões estruturais do corpo, é também a soma ou integral ao longo do trajeto do feixe de raios $X$ de todos os coeficientes de atenuação intrínsecos de cada região; então, torna-se necessário obter múltiplas projeções em diferentes locais em torno do objeto, assim, os coeficientes podem ser separados por um método de reconstrução de imagem, e mostrados de forma indireta como uma imagem (19).

Geralmente utiliza-se uma transformação linear entre os coeficientes de atenuação de um meio qualquer e da água, para definir uma escala de densidade relativa que é diretamente convertida em uma escala de tons de cinza, com o objetivo de representar em uma tela as tonalidades de cinza que são utilizados para representar uma imagem. A escala Hounsfield é definida a seguir:

$$
U H=1000 \cdot \frac{\mu_{t}-\mu_{a}}{\mu_{a}}
$$


onde $\mu_{a}$ é o coeficiente de atenuação linear da água, e $\mu_{t}$ é o coeficiente de atenuação linear do tessido, e UH é a Unidade Housnfield. A água é utilizada como o meio de referência, sendo a UH da água 0, e o UH do ar -1000 (19). Assim, cada pixel na tela de uma imagem tomográfica representa um valor de $\mathrm{UH}$, representativo tanto do tom de cinza quanto do coeficiente de atenuação linear relativo daquela posição no meio.

\subsection{Algorítmos de Reconstrução}

\subsubsection{Retroprojeção Simples}

Aqui, considera-se que o caminho que o feixe de raios $X$ percorre no corpo seja dividido em elementos igualmente espaçados, de maneira que cada elemento colabore com a mesma atenuação do feixe. A soma dos elementos atenuantes em várias projeções determina o coeficiente de atenuação para cada elemento. Este é um algoritmo direto, porém produz imagens borradas e artefatos.

\subsubsection{Retroprojeção Filtrada}

Este método utiliza uma equação integral unidimensional para a reconstrução de uma imagem 2D. Também conhecida como método da "Convolução", um filtro ou Kernel é utilizado para realçar as verdadeiras características do objeto. O Kernel é uma função 1D que é usada para deconvoluir as projeções 1D medidas antes da retroprojeção. Uma outra maneira de evitar o borramento é aplicar um Kernel 2D após a retroprojeção. Esse é o metodo mais popular usado para recosntruir imagens tomográficas.

\subsubsection{Transformada de Fourier}

Neste método, cria-se uma espaço de frequências. Aqui, aplica-se a transformada de Fourier 1D para cada projeção e cada ângulo, discretizando os dados de atenuação em frequências, também é tomada a transformada de fourier do Kernel que é aplicado na retroprojeção filtrada. No espaço de freguências ou inverso radial ocorre uma irnterpolação do espaço de coordenadas polares para coordenadas cartesianas, e a partir do sistema cartesiano inverso aplica-se a transformada inversa de Fourier 2D 
para se obter uma imagem. O cálculo com o método da transformada de Fourier é mais rápido, e demanda menos poder de processamento $(1,19)$.

\subsubsection{Método Iterativo}

Aqui, cálculos matemáticos tentam descobrir a forma final do objeto, através de comparações dos dados preditos com os dados físicamente medidos, as projeções. Há uma tentativa do software de sempre melhorar a qualidade e fidelidade da imagem a cada iteração. Esse processo se inicia com uma tentativa de saber com o que o objeto pode parecer, essa previsão é utilizada para calcular as chamadas projeções avançadas, que são então comparadas com as projeções físicas. A partir dessa comparação, uma matriz de erros é construída, e a cada iteração há uma tentativa do algorítmo reduzir essa matriz de erros abaixo de um limite aceitável, o que se chama de convergência, assim, a imagem construída é uma boa estimativa da imagem do objeto real que foi digitalizado.

Os algorítmos iterativos podem modelar o espectro de raios $\mathrm{X}$, o borramento do ponto focal, além de aproveitar melhor o dados adquiridos, como por exemplo, imagens com maior razão sinal ruído a partir da mesma dose, ou mesma razão sinal ruído a partide de doses menores(1).

\subsubsection{Feixe Cônico}

Este método é parecido com método para feixe em leque, porém aqui, é levado em consideração além do ângulo de abertura do feixe leque também o ângulo de abertura do cone, que agora possui divergência devido à geometria do feixe. Aqui o método utilizado é o de retroprojeção filtrada que é calculado para os dois tipos de ângulos de abertura, e a reconstrução da imagem é realizada em todo o volume de maneira simultânea. O método mais conhecido é o algoritmo de Feldkamp, Davis, e Kress (FDK) que em sua forma original, assume que os dados são adquiridos a partir de um detector plano.

Modalidade definida pela geometria do feixe, o feixe cônico pode alcançar orgãos inteiros em apenas uma rotação. Detectores com matriz de $512 \times 512$ são utilizados. O algorítmo de reconstrução da imagem, agora deve levar em conta o ângulo cônico, que pode variar entre os fabricantes e pela colimação. Tempos de aquisição variam entre 5 s e 40 s e o potencial gerador de 40 a 120 kVp (20). A principal desvantagem 
da Tomografia Computadorizada de Feixe Cônico (TCFC) é o grande espalhamento do feixe, prejudicando a resolução de contraste e resolução espacial.

\subsection{Modos de Aquisição}

\subsubsection{Axial ou Sequencial}

Geralmente conhecida como passo e atira, o tubo de raios X leva em torno de 0,5 s para completar $360^{\circ}$ em volta do paciente. Nessa modalidade, o tubo de raios $\mathrm{X}$ não fica ligado durante o movimento da mesa, ou seja, após a aquisição de uma fatia, o feixe é desligado, ocorre o deslocamendo da mesa para a próxima região alvo, o feixe é ligado, e assim por diante até completar a cobertura do volume especificado. O Tempo de aquisição é maior em relação ao TC helicoidal, devido ao fato da parada do feixe, deslocamento da mesa, e ligada do feixe.

\subsubsection{Helicoidal ou Espiral}

Aqui não existe parada, a rotação do feixe de raios $X$ e o deslocamento da mesa ocorrem de maneira simultânea. A principal vantagem da técnica helicoidal é a velocidade de aquisição. O pitch descreve o avanço da mesa em cada rotação, como representado na equação 1.14. Um pitch igual a 1, significa que a imagem é sequencial; um pitch menor que 1 significa que há uma sobreposição da imagem e consequentemente do feixe, o que leva a um aumento na dose; um pitch maior que 1 significa que há espaçamendo entre as imagens de uma rotação completa, isso diminui a dose. A relação entre pitch e dose é da seguinte forma:

$$
\text { Dose }=1 / \text { pitch }
$$

O fator chave para a ampla utilização da TC é a velocidade de aquisição, por exemplo, uma aquisição de pelve com $48 \mathrm{~cm}$ de comprimento leva em torno de 6 segundos para ser concluída, tempo que se pode prender a respiração e evitar artefatos por movimento. 


\subsubsection{CT Cardíaca}

Para tomadas de imagem do coração, é necessário uma alta resolução temporal, sendo a taxa de batimento cardíaco em torno de 60 ciclos por segundo, lavase $1 \mathrm{~s}$ para cada ciclo, assim para não adicionar artefatos de movimentos durante a aquisição, um tempo ótimo de aquisição de $100 \mathrm{~ms}$ seria suficiente. Para resolver esse problema, uma TC com características próprias e bastante diferentes foi desenvolvida, aqui, utiliza-se um feixe de elétrons gerados e acelerados por um acelerador linear, onde esse feixe é dirigido magneticamente em anéis de tungstênio colocado sobre o paciente, assim ocorre a produção de raios $X$ na forma de um leque, que é transmitido aos anéis de detectores acima do paciente. Os anéis de detectores abrangem 180 graus mais o angulo leque. Por essa técnica, pode-se ocorrer uma rápida cicundação do feixe em torno do paciente, alcançando uma resolução temporal de 50 ms.

TC de terceira geração (rotação / rotação) e sétima geração ( helicoidal multidetector) também podem adquirir imagens cardíacas devido à largura da linha de detectores $n T$. Aqui utiliza-se o sistema de gatilho retrospectivo, onde a aquisição será fragmentada e não contínua, em regiões temporáis específicas do ciclo cardíaco. Uma outra técnica é adquirir projeções aleatórias ao longo do ciclo cardíaco, esse tipo de aquisição possui o gatilho de disparo de raios $X$ sincronizado com o eletrocardiograma (ECG), que durante a recostrução da imagem, o algorítmo indentifica as projeções radiográficas com a coordenada temporal do ciclo cardíaco e uma imagem 3D dinâmica pode ser reconstruída, ilustrando a batida do coração. A principal aplicação da TC cardíaca é visualizar bloqueios das artéria coronárias, assim como estenóses coronárias.

\subsubsection{Dupla Energia}

Em meados de 1970, Hounsfiel previa a utilização da tomografia com energia dupla para decompor a densidade elementária da composição material. Hoje em dias atuais, é utilizada para imagens cardíacas. 


\subsubsection{Angiografia}

A técnica de imagem TC possui maior resolução de contrate que a angiografia convencional, além de utilizar contraste intravenoso que é menos invasivo que o acesso arterial utilizado em angiografia baseada em fluoroscopia.

\subsubsection{Perfusão}

Os estudos perfusão através da TC são relativamente de alta dose, uma vez que várias aquisições no mesmo local são realizadas para quantificar o fluxo sanguíneo em tempo real em determinado orgão. É utilizada para avaliar acidentes vasculares e vasoespasmos cerebrais, perfusão vascular e outras características fisiológicas relacionadas ao fluxo de sangue no orgão.

\subsubsection{Modulação de Dose}

Durante a aquisição da imagem, o feixe de raios $X$ precisa atravessar regiões mais espessas que outras, simplesmente pelo fato do corpo não ser um cilindro perfeito, então espessuras laterais são maiores que espessuras anteroposteriores. Assim, níveis de sinais mais altos são combinados com níveis de sinais mais baixos, e a imagem fica com um ruído não uniforme, então, uma variação do $m A$ pode solucionar esse problema. Na modulação de dose, o $m A$ para espessuras menores é mais baixo em relação ao $m A$ para espessuras maiores. Assim, níveis de dose podem ser menores para se alcançar a mesma qualidade de imagem. 


\section{Revisão da Literatura}

ROBERTS e col. (21) avaliaram a dose efetiva utilizando dosímetros termoluminescentes posicionados em cada orgão específico considerado como radiosensível de um objeto simulador antropomórfico. Eles utilizaram, os fatores de peso para orgãos a partir da ICRP 1990 (22) e da ICRP 2007 (23), e constataram em uma comparação entre as doses que para as glândulas salivares quando completamente irradiadas, a dose considerando os fatores mais recentes quase dobrou comparada com os fatores de 1990, e de uma maneira geral, as diferenças entre as doses abrangentes dos outros orgãos foram significantes. A TCO utilizada foi o i-CAT com potencial de $120 \mathrm{kVp}$, a dose efetiva dobra para protocolos de alta resolução, isso se dá pelo fato do número de projeções ser quase duas vezes maior.

TORRES e col. (24) avaliaram o PDA (produto dose área) e a E para diferentes protocolos utilizando tamanhos de voxel variáveis, com o objetivo de melhorar os parâmetros baseados nos princípios de radioproteção. Concluiram que o tamanho do voxel não influencia o valor da dose caso os parâmetros de exposição como kvp, $\mathrm{mAs}$, permaneçam constantes. Caso a utilização de voxel maior combinado com mAs e tempo de exposição reduzidos, uma redução de dose em torno de $50 \%$ pode ser alcançada.

HELMROT e col (25) procuraram provar uma metodologia para monitoração da dose para radiologia odontológica com maior atenção para TCO. Citaram que é importante a verificação dos níveis de dose para otmização dos parâmetros de exposição, e comparação de risco e qualidade de imagem. $O \mathrm{P}_{\mathrm{KA}}$ foi a grandeza sugerida para avaliar o níveis de dose, e pode ser obtido por uma câmara de transmissão, além de poder ser usado como padrão de dose e ainda se tornar a grandeza dosimetrica para definição dos níveis de referência de dose em radiodiagnóstico odontológico. Para a derivação dos coeficientes de conversão para dose efetiva, o volume do corpo e os parâmetros de exposição devem ser considerados, ou seja, para estabelecer NRR é necessário conhecer também a voltagem do tubo $(\mathrm{kVp})$, a carga (mAs), tempo de 
exposição (s) e a filtração do feixe. Assim, concluiram que o $P_{K A}$ pode ser utilizado para monitoração da dose, e ainda estabelecer protocolos de exposição.

HAN e col. (26) sugeriram uma avaliação dos níveis de referência de radiodiagnóstico (NRR) utilizando o produto dose área (PDA)como parâmetro dosimétrico. O estudo abrangeu não só a tomografia, mas também a radiografia intraoral, cefalometria e panorâmica. O método usado para definir os NRRs, parte do cálculo dos quartis, onde o terceiro quartil, é o valor de referência para estabelecer um NRR, porém no estudo em questão, essa metodologia ainda não havia sido utilizada para a tomografia. Os valores de PDA encontrados para os equipamentos ficam entre 1000 e $3200 \mathrm{mGy} \cdot \mathrm{cm}^{2}$, e percebeu-se uma correlação mais forte entre PDA e o tamanho do CDV do que com o mAs; e ainda, comparando-se TCO com detectores Flat Panel Detector (FPD) e de carga acoplada (CCD), observou-se que a dose nos sensores FPD são 1,5 vezes maiores que os valores observados no CCD, mas as diferenças entre as dose e CDV foram similares para os dois tipos de sensores, desta forma, torna-se evidente indicar o tamanho adequado do CDV para cada região de interesse.

PAUWELS e col. (27) procuraram estimar a dose absorvida no orgão e a dose efetiva para uma ampla variedade de TCOs. Eles utilizaram dois objetos simuladores antropomórficos usados em radioterapia, onde as doses foram estimadas a partir de dosímetros TLDs colocados em posições específicas representativas dos orgãos radiosensíveis cobrindo todo o pescoço e cabeça, e os fatores de ponderação do tecido para dose efetiva foram os publicados na ICRP 2007 (23). 14 TCOs foram utilizadas na pesquisa, pois uma grande variedade de tamanhos de CDV e geometrias foram avaliados. A faixa de dose ficou entre $19 \mu \mathrm{Sv}$ e $368 \mu \mathrm{Sv}$ onde as maiores contribuições para dose efetiva foram observadas para a tireóide (21\%), glândulas salivares (24\%) e tecidos remanescentes (37\%). Os fatores de exposição, tamanhos do CDV, e o posicionamento dos orgãos em relação ao feixe, são os fatores que desencadeiam uma ampla variação nos valores de doses. É necessário que os tamanhos dos CDVs sejam separados em categorias como CDVs pequenos, médios e grandes, pois, essa distinção discretiza a aplicação dos protocolos pra grupos de pacientes específicos e aplicações específicas, onde a dose é diretamente proporcional ao tamanho do CDV.

BATISTA e col. (28) avaliaram a dose em radiografias panorâmicas a partir de equipamentos convencionais e TCO, utilizando fatores de conversão para se derivar a dose efetiva. $O \mathrm{P}_{\mathrm{KA}}$ e o $\mathrm{P}_{\mathrm{KL}}$ foram as grandezas dosimétricas para avaliar as diferentes técnicas, uma vez que o Kerma no ar na superfície de entrada $\left(K_{e}\right)$ não é aplicável 
devido a natureza estreita do feixe de radiação para equipamentos panorâmicos convencionais. A avaliação da dose efetiva foi obtida a partir dos fatores de conversão do $\mathrm{P}_{\mathrm{KA}}$ para dose defetiva que são derivados experimentalmente ou por simulação Monte Carlo e possui o seguinte valor: $E / P_{K A}=0,008 \mathrm{mSv} / \mathrm{Gy} \cdot \mathrm{cm}^{2}$, onde resultados experimentais informam um dependência energética considerável, que deve ser levada em conta. Os valores de dose efetiva encontrados são quatro vezes maiores para as panorâmicas obtidas através de reconstrução 2D a partir da TCO quando comparadas com o equipamento convencional, fato que não justifica a substituição do método convencional, exceto quando a aquisição volumétrica é justificada.

LI e col. (29) investigaram os níveis de doses recebidos pelos pacientes que são submetidos ao exame de TCO, comparando esses níveis de doses com os encontrados para radiografia odontológicas convencionais e Tomografia Computadorizada Multi-Slice (MSCT), e buscaram também os métodos que podem ser utilizados para reduzir esses níveis de dose, sem afetar a qualidade da imagem. As doses nos pacientes são bem maiores em MSCT comparadas com TCO, porém a qualidade de imagem para tecido ósseo é melhor na TCO, e para a visualização da anatomia de tecido mole o MSCT se destaca. As doses a partir da TCO estão relacionadas com os parâmetros de exposição e tamanho do CDV, a dose pode chegar a ser centenas de vezes maiores que as radiografias convencionais. A utilização de alguns aparatos de proteção demonstrou sua efetividade na redução de dose em alguns orgãos em questão, onde os protetores de pescoço podem reduzir a dose na tireóide e no esôfago por $48,7 \%$ e $41,7 \%$ respectivamente, e o uso de óculos plumbífero pode reduzir até $60 \%$ nas lentes dos olhos.

ARAKI e col. (30) buscaram uma correlação entre os índices de dose em TCO e o PDA, com o objetivo de avaliar a variação relativa para cálculos de dose efetiva. Os índices de dose utilizados foram os propostos pelo projeto SEDENTEXCT onde o índice 1 é a média das medidas realizadas ao longo de uma linha representativa do diâmetro do objeto simulador, e o índice 2 é calculado a partir da dose média central mais a dose média na periferia, ambos divididos por dois. Encontrou-se então um fator de correlação maior entre o índice 2 e as medidas de PDA comparados com o índice 1. Dessa forma foi sugerido que o PDA deve ser aplicado como NRR para TCO, e mesmo assim, os índices propostos pelo projeto SEDENTEXCT são fáceis e práticos de executar. 
ANDRADE e col. (31) avaliaram a dosimetria para planejamento de implantes a partir da TCO. Eles realizaram uma comparação entre dois tomógrafos, ICAT Classic e Prexion 3D, onde foi utilizado o produto Kerma no ar área e o Kerma no ar na superfície de entrada $\left(\mathrm{K}_{\mathrm{i}}\right)$, avaliados na região dos olhos, glândulas submandibulares, parótidas e tireóide. Comparou-se o $P_{K A}$ dos ICAT e Prexion levando-se em cosideração o tamanho do CDV, o tempo de aquisição, tempo de exposição, modo de exposição, resolução. Verificou-se que o $\mathrm{P}_{\mathrm{KA}}$ é proporcional ao $\mathrm{mAs}$ e ao tamanho do CDV e também à resolução da imagem, pois protocolos de alta resolução utilizam tempo de exposição maiores, devido a necessidade de se reduzir o ruído quântico associado ao número de fótons que chegam ao detector. Observou-se também que a variação do Kerma no ar na superfície de entrada é variável com o tamanho do CDV, e que isso se deve ao fato da posição dos orgãos em relação às bordas superior e inferior do CDV. Andrade e col. conlcluiram que ao utilizar protocolos de aquisição específicos para cada situação e paciente, assim como uma redução do CDV, ajudam a diminuir a dose no paciente; e a utilização de um modo pulsado para o feixe de radiação, como do iCAT, também é uma importante consideração para a redução de doses em equipamentos TCO em geral.

LUDLOW e WALKER (32) estudaram as doses resultantes de várias combinações de CDV, localização, parâmetros de exposição, utilizando objetos simuladores de criança e adulto, dosímetria TLD e OSL (Optically Stimulated Luminescent) com exposiçoes realizadas no i-CAT FLX. As doses medidas foi uma combinaçãos dos diferentes tamanhos de CDV, e localizações dos orgãos comparando os objetos simuladores de criança e adultos, e os protocolos utilizados foram alta resolução, resolução padrão, aquisição rápida, e aquisiçao rápida (plus). Os resultados evidenciaram que a dose no objeto simulador criança é 36\% maior que no adulto, e que protocolos de aquisição rápidos resultam em uma redução significativa da dose no paciente, pois chegam a ser comparados com doses a partir de radiografias panorâmicas, porém a redução na qualidade de imagem e perceptível .

BATISTA e col. (33) propuseram um objeto simulador de baixo custo e uma metodologia associada para avaliação dosimétrica em TCO. Este objeto simulador possui dimensões características a de uma face humana, construído com material poli-metilmetacrilato (PMMA) que foi preenchido com água. Foi proposto também uma grandeza dosimétrica, o produto altura - índice de Kerma $\mathrm{P}_{\mathrm{KIH}}$. Observou-se que os perfis de Kerma através dos CDVs com grandes diâmetros foi uniforme, e não uniformes para CDVs pequenos. Os índices de Kerma, foram maiores para os CDVs pequenos, com- 
parados com CDVs grandes, assim tais resultados indicam que há um necessidade de utilizar objetos simuladores especiais para dosimetria em TCO, o $\mathrm{P}_{K A}$ poder ser um parâmetro enganoso, e necessita-se a busca de novos índices de dose alternativos.

KIM e col. (34) derivaram os fatores de conversão para dose efetiva utilizando o $\mathrm{P}_{\mathrm{KA}}$ medido para vários protocolos referentes a um único equipamento de TCO. Foi utilizado uma câmara de placas paralelas com respectivo eletrômetro para aferir diretamente o $\mathrm{P}_{\mathrm{KA}}$, a dose efetiva foi calculada a partir de fatores de ponderação do tecido vigentes na ICRP 2007 (23), utilizando dosímetros termoluminescentes colocados em regiões específicas em um objeto simulador antropomórfico. A faixa de valores de $P_{K A}$ para o equipamento Alphard VEGA CBCT foi de $644 \mathrm{mGy} \cdot \mathrm{cm}^{2}$, com uma faixa de dose efetiva entre $22 \mu \mathrm{Sv}$ a $304 \mu \mathrm{Sv}$. O estudo demonstrou a viabilidade em derivar-se os fatores de conversão a partir do $P_{K A}$.

PAUWELS e col. (35) estimaram o risco de câncer a partir de exposições TCO baseado na dose de entrada na pele para as principais indicações do exame que são: planejamento de implante, dentes inclusos, tratamento e planejamento ortodônticos, traumas, tumores, anormalidades e seios maxilares. Para a estimativa dos riscos mediu-se a dose de entrada na pele utilizando-se dosímetros termoluminescentes posicionados na superfície da pele, também foram utilizados TLDs dentro dos orgãos para se estimar a dose no orgão, e a relação entre essas duas grandezas dosimétricas variou devido aos diferentes parâmetros de exposição como tamanho e posição do CDV e kVp. A partir dos fatores de conversão de dose na pele para dose no orgão e os fatores de ponderação do tecido a partir da ICRP 2007 (23), estimou-se as doses efetivas indivíduais, e a partir destas os riscos de cânceres atribuídos ao tempo de vida usando os fatores de risco por BEIR VII (2006)(36). As doses de entrada na pele para a tireóide foram maiores para alguns equipamentos devido ao posicionamento do feixe de radiação estar mais baixo, o que aumenta de maneira significativa o risco de câncer, mas isso pode ser evitado deslocando o CDV em direção cranial. Observou-se também que a dose de entrada na pele não é dependente a partir do índice de massa corporal (IMC). Os riscos de cânceres podem ser dependentes de uma população específica. Como esperado, os riscos considerados para pacientes jovens e crianças, são maiores comparados com os riscos para adultos, e sempre será, devido ao efeito da idade. Pacientes de 3 anos e 5 mêses, fêmea, possui uma fator de risco 5,4 vezes maior comparado com um adulto de 30 anos. 
PAWELS e col. (37) caracterizaram a distribuição de dose para várias unidades TCOs, investigando tamanhos de CDVs, geometrias de rotação, e diferentes aplicações clínicas. Eles utilizaram objetos simuladores de água do tamanho de uma cabeça humana confeccionados com PMMA, no qual foram inseridos dosimetros TLDs, câmaras de ionização e filmes radiocrômicos. O experimento mostrou que a forma e a distribuição do gradiente de dose depende do tamanho e posição do CDV, e também no tipo de rotação, além disso, o espectro caracterizado pela voltagem e filtração também são fatores de influência. A definição de um índice de dose deve ser sensível aos diferentes fatores de exposição, além de geometrias de feixes, variação do posicionamento, e rotações parciais. A derivação de fatores de conversão entre índices de doses para doses efetivas, quando aplicados a TCO, deve-se tomar extremo cuidado, devido a variação no percetual do volume irradiado, que é diretamente dependente da geometria do feixe e posicionamento, assim, nessa linha de raciocínio, simulações Monte Carlo pode ser usada para investigar esses fatores de conversão. Conclui-se que a derivação de um índice de dose ótimo não é possível, devido a quantidade de variáveis que influencia a metodologia dosimétrica.

SUOMALAINEN e col. (38) avaliaram a dose de radiação para quatro TCOs, e compararam com dois MSCT. As doses foram estimadas a partir de dosímetros TLDs inseridos em objeto simulador antropomórfico, e utilizou-se também um objeto simulador especial cilíndrico pra avaliar a qualidade da imagem pela razão contraste-ruído (RCR) e pela função de tranferência modular (FTM). Os fatores de ponderação de tecido foram usados a partis da ICRP 1990 E ICRP 2008, onde as faixas de doses verificadas foram 14 a $269 \mu$ Sv e 27 a $674 \mu$ Sv respectivamente para TCOS; já para MSCTs, os valores encontrados foram 350 a $742 \mu$ Sv e 685 a $1410 \mu$ Sv respectivamente. A RCR para TCO foi $8,2-18,8$ e MSCT 13,6 - 20,7, onde para protocolos de baixa dose, a RCR dos MSCTs se igualam aos TCOs. A FTM variou entre $0,1 \mathrm{~mm}^{-1}$ e $0,8 \mathrm{~mm}^{-1}$ para TCO, e para MSCT foi constante e igual a $0,5 \mathrm{~mm}^{-} 1$. A partir destes resultados, foi observado que a RCR e a MTF são fortemente influencidas pelos filtros utilizados na reconstrução da imagem tomográfica; e a distribuição de dose é afetada pelo tamanho do CDV. A TCO pode ser utilizada na odontologia, por fornecer boas imagens e doses menores que MSCT, mas uma otimização dos parâmtros de exposição, deve ser realizadas em ambos tipos de TC.

OLIVEIRA e col. (39) avaliaram a influência do CDV nas medidas de $P_{K A}$ juntamente com a constância dos parâmetros de exposição. As medidas de $\mathrm{P}_{\mathrm{KA}}$ ficaram entre $360,1 \mathrm{mGy} \cdot \mathrm{cm}^{2}$ e $1031,2 \mathrm{mGy} \cdot \mathrm{cm}^{2}$, e a avaliação da repetitibilidade e exatidão 
da tensão no tubo ficaram dentro do aceitável, ou seja, abaixo de 10\%, e aferiu-se também uma relação direta com a altura do CDV , e inversa com relação ao diâmetro do CDV.

SIGNORELLI e col. (40) determinaram as doses de radiação para diferentes protocolos de aquisições TCO para comparar com radiografias ortodônticas convêncionais utilizando um objeto simulador antropomórfico. Signorelli e col questionam o benefício a partir da TCO considerando que a maioria dos pacientes ortodônticos são jovens e crianças em crescimento, o que de certa forma aumenta a dose efetiva uma vez que são pacientes menores e em fase de crescimento, fato que evidencia a necessidade de protocolos específicos para cada tipo de paciente, pois o princípio ALARA (As Low As Reasonably Achievable) garante a otimização de dose. A exposição de crianças pode desencadear danos ao DNA, mesmo que o nível de radiação seja baixo e inferior ao limite de carcinogênese, avaliar os riscos e benefícios é uma tarefa extremamente desafiadora. As radiografias necessárias durante o tratamento devem ser adquiridas quando realmente necessárias, tendo-se a consciência dos riscos e benefícios. A TCO não deve ser indicada para todos os pacientes submetidos ao tratamento ortodôntico, uma vez que as radiografias convêncionais expõe níveis menores de radiação, mesmo considerando a completeza de uma imagem volumétrica. Blindar orgãos considerados radiosensíveis como a tireóide deve ser praticado na rotina para reduzir a dose no paciente.

BATISTA e col. (41) avaliaram a ditribuição de dose na superfície de entrada durante a aquisição de tomografia computadorizada de feixe cônico (TCFC), e calcularam a dose no orgão envolvidas nos procedimentos de imagem guiada em radioterapia, utilizando simulação computacional Monte Carlo, e para validar os valores, os resultados obtidos foram comfrontados com valores de CTDI medidos a partir de uma câmara de ionização tipo lápis de 100 mm e objeto simulador específico. Observou-se uma boa concordância entre os valores de CTDI simulados e medidos, diferenças até $17 \%$, o que valida de maneira satisfatória as simulaçãos Monte Carlo. Avaliação de dose no orgão deve ser realizada levando-se em consideração o tratamento terapêutico e as doses de imagem TCFC, e a importância da consciência em relação ao risco aumentado quando ocorrerem exposições repetidas. 


\section{$3 \quad$ Materiais e Métodos}

Os tomógrafos utilizados neste estudo foram cedidos por clínicas de radiologia odontológica particulares, exceto OP300 cedido pela Faculdade de Odontologia de Ribeirão Preto - USP. Cada tomógrafo com suas características intrínsecas de aquisição, colimação, e variações dos protocolos de exposição, estão descritos a seguir. As especificaçõs técnicas para cada TCO foram consultadas nos respectivos manuais do usuário, quando disponíveis, como fabricante, modelo, tipo de exposição, tamanho do ponto focal, e filtração total descritas na Tabela 1.

Tabela 1: Especificações técnicas referentes aos tomógrafos de feixe cônico odontológicos

\begin{tabular}{lllccc}
\hline Fabricante & Modelo & Exposição & $\begin{array}{c}\text { kVp } \\
\text { Ponto focal } \\
\text { mm }\end{array}$ & $\begin{array}{c}\text { Filtração } \\
\mathrm{mmAl}\end{array}$ \\
\hline Imaging Sciences & i-CAT FLX & pulsado & 120 & 0,5 & 10 \\
Imaging Sciences & i-CAT Classic & pulsado & 120 & 0,5 & 10 \\
Dabi Atlante & Eagle 3D & contínuo & 85 & 0,5 & 3,05 \\
Tera Recon & Prexion 3D & contínuo & 90 & 0,2 & - \\
VATECH & PAX - Uni3D & contínuo & 85 & 0,5 & - \\
Instrumentarium & OP300 & pulsado & 90 & 0,5 & 3,2 \\
SOREDEX & CRANEX 3D & pulsado & 90 & 0,5 & 3,2 \\
\hline
\end{tabular}

Todos os equipamentos descritos acima possuem detectores Flat Panel para aquisição da imagem, pois possuem alta resolução espacial e grande faixa dinâmica, são menos volumosos e complicados comparados com os intensificadores e dispositivos de carga acoplada. Estes últimos tem se tornado obsoletos em TCO. FPD é uma matriz de pixels de sílica amorfa compreendida em um thin film transistors (TFT) ou complementary metal oxide semiconductors (CMOS) (20). 


\subsection{Testes de Controle de Qualidade}

Para aferir os parâmetros descritos a seguir, utilizou-se o medidor multipropósito PTW DIAVOLT.

Camada Semirredutora: avalia a qualidade do feixe de raios X. Placas de alumínio com $99 \%$ de pureza foram postas entre a fonte e o detector para atenuação do feixe. Realizou-se inicialmente medições sem placas para aferir o valor Kerma no ar sem atenuação $K_{0}$, e logo em seguida adicionou-se as placas para atenuar o feixe até os valores superior e inferior à metade do valor do Kerma no ar inicial. De posse destes dados, a equação a seguir foi utilizada para a interpolar o valor da CSR.

$$
C S R=\frac{x_{b} \ln \left(2 \cdot \frac{K_{a}}{K_{0}}\right)-x_{a} \ln \left(2 \cdot \frac{K_{b}}{K_{0}}\right)}{\ln \left(\frac{K_{a}}{K_{b}}\right)}
$$

onde $\mathrm{K}_{\mathrm{a}}$ é a leitura do Kerma imediatamente superior a $\mathrm{K}_{0} / 2, \mathrm{~K}_{\mathrm{b}}$ é a leitura de exposição imediatamente inferior a $\mathrm{K}_{0} / 2, \mathrm{x}_{\mathrm{a}}$ é a espessura de Al correspondente à leitura $\mathrm{K}_{a}, \mathrm{x}_{\mathrm{b}}$ é a espessura de $\mathrm{Al}$ correspondente à leitura $\mathrm{K}_{b}$. Não há valores mínimos de referência para CSR aplicados à TCO.

Rendimento do tubo de Raios X: avalia o Kerma no ar produzido por unidade de carga do tubo.

$$
\text { Rend }=\frac{\bar{K}}{m A s} \cdot D F D^{2}
$$

em que $\overline{\mathrm{K}}$ é a média do Kerma no ar, mAs é a carga do tubo, e DFD ${ }^{2}$ é o fator de correção para a distância fonte detector de $1 \mathrm{~m}$ dado $\mathrm{em} \mathrm{m}^{2}$. A DFD foi aferida por trena. Não há valores de referência, o rendimento é tomado como o fator de desgaste ao longo do tempo.

Repetitividade e Exatidão do kV: testa o grau de concordância entre várias medidas do kV, além de verificar a discrepância do valor medido para o nominal. Para a exatidão segue a equação:

$$
d(\%)=100 \cdot \frac{k V p_{\text {nom }}-k V p_{\text {medio }}}{k V p_{\text {nom }}}
$$

onde $k V p_{\text {nom }}$ é o valor nominal do potencial do tubo, $k V p_{\text {medio }}$ é a média das medições realizadas. 
Para a repetitividade:

$$
R(\%)=100 \cdot \frac{k V p_{\max }-k V p_{\min }}{\left(k V p_{\max }+k V p_{\min }\right) / 2}
$$

em que $k V p_{\text {max }}$ e $k V p_{\text {min }}$ são os respectivos valores máximo e mínimo das leituras realizadas do $\mathrm{kVp}$. Os valores achados para exatidão devem estar entre $\pm 10 \%$; e os valores para repetitividade $\leq 10 \%$.

\subsection{Medição $\mathbf{P}_{\mathrm{KA}}$}

Outro parâmetro de medição, o produto Kerma no ar-área $\left(\mathrm{P}_{\mathrm{KA}}\right)$, muito aplicado em técnicas de dosimetria para radiologia odontológica $2 \mathrm{D}$, como radiografias intra e extraorais e panorâmicas, foi utilizado para dosimetria da TCO. O $\mathrm{P}_{\mathrm{KA}}$ tem provado ser uma ferramenta bastante útil na quantificação de dose sem a presença do paciente ou objeto simulador específico. POPPE et al.(2007), LOOE et al. (2006) e TIERRIS et al. (2004) sugeriram para o cálculo dos níveis de refência de radiodiagnóstico o terceiro quartil dos valores de dose para radiografias odontológicas (42-45). O $\mathrm{P}_{\mathrm{KA}}$ é calculado a partir da medida do Kerma no ar por uma câmara de placas paralelas multiplicada pela área do feixe na mesma distância em que o detector foi posicionado, ou pode ser medido diretamente por um medidor de $\mathrm{P}_{\mathrm{KA}}$.

Durante a coleta de dados, em alguns equipamentos foi possível livre acesso, e tempo ilimitado para as dosimetrias, porém, em outros utilizou-se de horários préagendados durante horário comercial para realização das leituras, para estes casos, tomou-se os protocolos de uso mais frequentes em rotina clínica informados pelo técnico responsável.

Para medição do $P_{K A}$ utilizou-se uma câmara de placas paralelas PTW FREIBURG TV34049, utilizada para medir o produto Kerma no ár área paralelamente com a medida do Kerma incidente. Um eletrômetro associado PTW DIAMENTOR M4 - KDK capaz de ler $\mathrm{K}_{\mathrm{i}}$ e o $\mathrm{P}_{\mathrm{KA}}$. Este medidor já entrega o valor direto do produto Kerma no ár-área, simultâneamente com o Kerma incidente, porém as medidas de Kerma incidente não foram consideradas, devido a dificuldade de centralização da pequena câmara de ionização central com o eixo de simetria do feixe de raios $X$, o que ocasiona medidas errôneas e parcias dessa grandeza. Para este detector utilizou-se dois fatores de calibração, devido a dependência energética, para tomógrafos que trabaIham com 85 e $90 \mathrm{kVp}$ o fator de calibração é de $\mathrm{F}_{\mathrm{c}, 90}=1,56 \pm 0,01$ e para tomógrafos 
que operam em $120 \mathrm{kVp}$ o fator de calibração obtido foi de $F_{c, 120}=1,63 \pm 0,01$. Esses fatores de calibração foram obtidos a partir de um medidor $\mathrm{P}_{K A}$ modelo PDC (Paciente Dose Calibrator) fabricado pela Radcal, cedido pelo IPEN (Instituto de Pesquisas Energéticas e Nucleares), é um instrumento de referência para calibração de campos dos sistemas de medição e controle de dose, que possui validade entre as comparações inter-institucionais segundo informações do fabricante. A obtenção dos fatores de calibração foi pelo método da substituição, onde coloca-se o medidor de referência a uma distância fixa da fonte, com parâmetros de exposição fixos, e tomase as leituras, então, logo após, substitui-se o medidor de referência pelo medidor de prova, sem alterar os fatores de exposição, e na mesma distância da fonte inicialmente usada, toma-se a leitura. A divisão dos valores de referência pelos de prova, gera o fator de calibração para a câmara PTW.

A dosimetria dos equipamentos Eagle 3D, OP300, PAX Uni-3D, i-CAT Classic e Prexion 3D foram realizadas com o medidor PTW FREIBURG e corrigidas para a variação da temperatura e pressão a partir do fator de correção $\mathrm{K}_{T, P}$ definido a seguir. A dosimetria dos equipamentos i-CAT FLX e CRANEX 3D, foram realizadas com o medidor PDC Radcal.

$$
K_{T, P}=\left(\frac{273,2+T}{295,2}\right) \cdot\left(\frac{101,3}{P}\right)
$$

em que T e P é a temperatura em ${ }^{\circ} \mathrm{C}$ e a pressão em $\mathrm{kPa}$. Os valores de temperatura e pressão foram aferidos usando o termômetro e barômetro digital Oregon SCIENTIFIC EB 833.

\subsection{Nível de Referência de Radiodiagnóstico}

O $P_{K A}$ é o parâmetro dosimétrico utilizado para comparação e avaliação dos níveis de dose entre os diferentes equipamentos, além de permitir uma intercomparação dos protocolos diversos oferecidos por cada equipamento.

Para análise dos valores de doses medidos, devido a grande variedade de protocolos de aquisições e tamanhos de CDVs, os valores foram divididos em três classes, conceituando-as a partir da altura $(A)$ como $C D V s$ pequenos $(A<10 \mathrm{~cm})$, médios $(10 \leq A \leq 15 \mathrm{~cm})$ e grandes ( $\mathrm{A}>15 \mathrm{~cm}$ ). Essa definição proporciona uma comparação entre os protocolos e entre equipamentos mais restrita e igualitária (46). 
Para determinar os NRRs, utilizou-se as sugestões na literatura que aplicam o valor do $3^{\circ}$ quartil em uma amostra de dados específica. $03^{\circ}$ quartil é o valor que delimita os $25 \%$ maiores valores, ou seja, $75 \%$ dos valores são menores do que Q3 e $25 \%$ são maiores. Como o cálculo é feito através da ordenação dos dados, é necessário colocar os dados em ordem crescente, e calcular a posição dos quartis para cada amostra.O objetivo aqui é determinar NRRs para as aquisições aplicadas em endodontia, implante de maxila e mandíbula, e face total.

\subsection{Feixes Com Largura Nominal $>\mathbf{4 0} \mathbf{~ m m}$}

Os primeiros tomógrafos possuiam uma colimação de feixe de até $10 \mathrm{~mm}$, onde a câmara de ionização de 100 mm garantia que a radiação não medida no volume sensível poderia ser desprezada para larguras de feixe até $20 \mathrm{~mm}$. Porém, a evolução dos tomógrafos trouxeram os multifatias, com larguras de feixe de até $40 \mathrm{~mm}$. De-

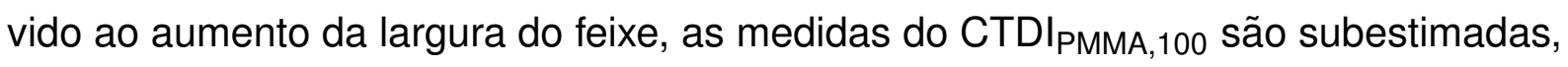
por não levar em consideração as caudas da radiação espalhadas. Os valores de dose máximos são alcançados em comprimentos de irradiação do objeto simulador de $300 \mathrm{~mm}$ para o corpo e $160 \mathrm{~mm}$ para cabeça. Além das dificuldades já mencionadas, deve-se levar em consideração os tomógrafos de feixe cônico que abrangem comprimentos irradiados de $160 \mathrm{~mm}$ em apenas uma rotação do tubo de raios $\mathrm{X}$, o que exemplifica que os parâmetros dosimétricos para essa modalidade de tomógrafo devem ser revisados e modificados.

Quando o primeiro tomógrafo de feixe cônico foi introduzido no mercado, verificouse uma necessidade de encontrar uma maneira apropriada e efetiva de medir as doses entregues por esses equipamentos. Grupos de pesquisas utilizaram objetos simuladores e câmaras de ionização longos para poderem cobrir todo o feixe, na estimativa do $\mathrm{CTDI}_{300}$, onde o comprimento de integração é $300 \mathrm{~mm}$, porém, manusear objetos simuladores desse porte, são as vezes impráticos sem os equipamentos corretos, e ainda as câmaras de ionização com comprimento de $300 \mathrm{~mm}$ além de serem caras, não são encontradas a pronta entrega.

Assim, na tentativa de avaliar a dose entregue para a tomografia de feixe cônico odontológica, onde o tamanho do CDV pode chegar a $22 \mathrm{~cm}$ de altura para protocolos de aquisição de face, utilizou-se a metodologia sugerida pelo protocolo de dosimetria da Agência Internacional de Energia Atômica (IAEA) 2011 (3), que considera para 
feixes acima de $40 \mathrm{~cm}$ de altura, que o $\mathrm{CTDI}_{\mathrm{w}, \mathrm{NT}}$ possa ser estimado a partir de medidas de referência no objeto simulador, corrigidas pela razão das medidas do CTDI livre no $\operatorname{ar}\left(\mathrm{CTDI}_{\mathrm{ar}}\right)$. O medidor usado para este método foi a câmara de ionização tipo lápis de 100 mm de comprimento, 3,14 cm³, PTW FREIBURG TN30009-0507 e o eletrômetro multileitor PTW UNIDOS E.

Então para feixes maiores de 40mm, o CTDI ${ }_{w}$ pode ser escrito como:

$$
C T D I_{w, N T}=C T D I_{w, R e f} \times\left(\frac{C T D I_{a r, 100, N T}}{C T D I_{a r, 100, R e f}}\right)
$$

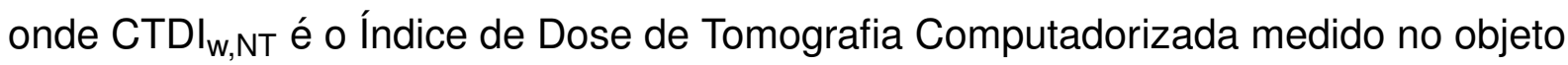

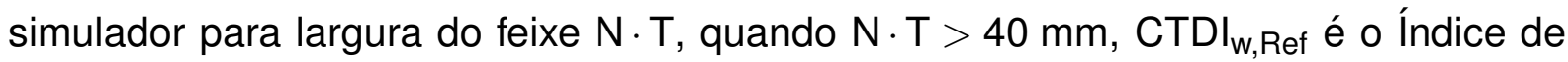
Dose de Tomografia Computadorizada medido no objeto simulador para a largura do feixe referência de $20 \mathrm{~mm}$ ou o mais próximo disso, CTDI $\mathrm{ar}_{\mathrm{a}, 100, \mathrm{NT}}$ e CTDI $\mathrm{Cr}_{\mathrm{ar}, 100, \text { Ref }}$ são os Índices de Dose de Tomografia Computadorizada medidos no ar para o comprimento de integração da câmara de ionização de $100 \mathrm{~mm}$ para a largura do feixe N · T e de referência $20 \mathrm{~mm}$ respectivamente $(3,13)$. A razão entre os índices no ar, é considerada ser igual a razão para os índices medidos no objeto simulador.

\subsection{Medição No Ar Para Feixes $>60 \mathrm{~mm}$}

A IAEA também apresentou uma metologia para mensurar o perfil de dose de radiação para tomógrafos que utilizam feixes largos maiores que $60 \mathrm{~mm}$. Uma aproximação é feita em torno da câmara de ionização de $100 \mathrm{~mm}$, para alcançar comprimentos de integração maiores, desloca-se a câmara de ionização ao longo do feixe (simetricamente) com intervalos de espaçamento igual ao comprimento da $\mathrm{Cl}$, onde uma medida é realizada em cada posição de maneira contínua, sem interposição do volume sensível, caso a interposição aconteça, o intervalo do feixe medido duas vezes, deve ser levado em consideração no cálculo final.

Se os deslocamentos forem contínuos igual o comprimento da $\mathrm{Cl}$, a integral de dose total é a soma de uma série de medidas ao longo do feixe, descrita a seguir:

$$
C T D I_{a r}=\frac{1}{N T} \times \sum_{i=1}^{i=n}\left[\int_{0}^{L_{c}} D_{i}(z) d z\right]
$$

onde n é o número de passos dados ao longo do feixe (3). Nota-se que esse método é implementado no eixo central (z), e não reporta uma distribuição axial da dose 


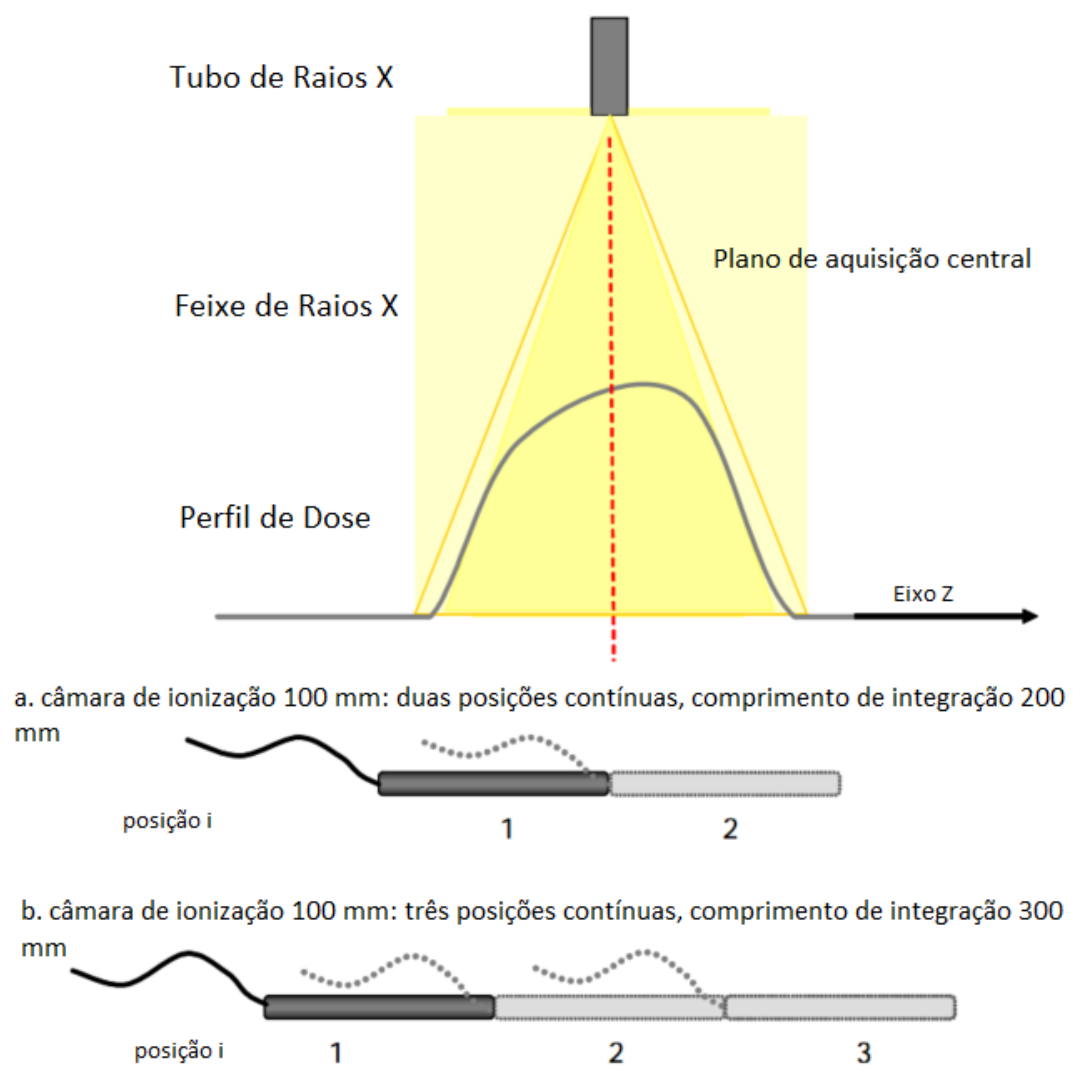

Figura 6: Ilustração dos deslocamentos realizado com uma $\mathrm{Cl}$ de $100 \mathrm{~mm}$ tipo lápis, para cobrir todo o feixe. Adaptado de: IAEA TechReport (3)

como no $C T D I_{\mathrm{w}, 100}$, pois não são realizadas medidas na borda do CDV, é uma medida de perfil unidimensional que visa a cobertura eficiente do feixe, e não leva em consideração a radiação espalhada, que no caso do ar, é irrelevante. Pode-se usar para essa metodologia camaras maiores como $\mathrm{Cl}$ tipo lápis de $300 \mathrm{~mm}$, detectores de estado sólido, e $\mathrm{Cl}$ tipo dedal, desde que calibradas para o espectro do feixe em questão. O experimento realizado aferiu os valores do CTDI PMMA,100 e o CTDI $_{\text {PMMA,300 }}$ a partir dos deslocamentos da $\mathrm{Cl}$ de $100 \mathrm{~mm}$. Essa metodologia foi utilizada apenas para O iCAT e Prexion. 


\section{Resultados}

Verificar a capacidade de funcionamento do equipamento, assim como sua aptidão pra realizar a tomada de imagens, é uma questão premissa para o controle de qualidade da imagem e dosimetria de um serviço de radiodiagnóstico. Portanto o controle de qualidade foi realizado a partir das medições da CSR, rendimento do tubo de raios $X$, repetitividade e exatidão do $k V p$, descritos na Tabela 2. Estes dados foram coletados utilizando o medidor PTW DIAVOLT.

Tabela 2: Resultados obtidos para CSR, rendimento, repetitividade e exatidão do kVp medidos para cada equipamento

\begin{tabular}{ccccc} 
Equipamento & CSR & $\begin{array}{c}\text { Rendimento } \\
\mathrm{mmAl}\end{array}$ & $\begin{array}{c}\text { Repet. kVp } \\
\mu \mathrm{Gy} / \mathrm{mAs}\end{array}$ & $\begin{array}{c}\text { Exatidão kVp } \\
\%\end{array}$ \\
\hline CRANEX 3D & $5,46 \pm 0,05$ & $15,50 \pm 0,34$ & $0,22 \pm 0,14$ & $-6,59 \pm 0,17$ \\
Eagle 3D & $5,70 \pm 0,07$ & $31,77 \pm 0,20$ & $0,22 \pm 0,16$ & $-6,58 \pm 0,18$ \\
i-CAT Classic & $9,79 \pm 0,06$ & $35,74 \pm 0,03$ & $0,60 \pm 0,11$ & $-9,38 \pm 0,19$ \\
i-CAT FLX & $9,70 \pm 0,07$ & $36,66 \pm 0,04$ & $0,22 \pm 0,10$ & $-10,61 \pm 0,40$ \\
OP 300 & $6,11 \pm 0,02$ & $11,88 \pm 1,19$ & $0,11 \pm 0,16$ & $1,63 \pm 0,13$ \\
Prexion 3D & $4,41 \pm 0,08$ & $40,10 \pm 0,22$ & $0,11 \pm 0,15$ & $-2,40 \pm 0,12$ \\
Pax-Uni 3D & $5,00 \pm 0,10$ & $14,04 \pm 0,07$ & $0,11 \pm 0,16$ & $-3,33 \pm 0,11$ \\
\hline
\end{tabular}

Os dados mostrados acima, informam qual a qualidade do feixe utilizado, e o quanto de radiação é produzido por unidade de carga do tubo, com destaque para os i-CAT, onde os valores de CSR são os maiores, e também com os maiores rendimentos do tubo de raios X. O menor rendimento foi encontrado para o OP300, e a menor CSR para o Prexion 3D. 


\subsection{Resultados $\mathrm{P}_{\mathrm{KA}}$}

As seguintes tabelas, apresentam os resultados obtidos para as medições de $\mathrm{P}_{\mathrm{KA}}$.

A Tabela 3 mostra os valores de $\mathrm{P}_{\mathrm{KA}}$ para o CRANEX 3D, onde cada protocolo está descrito pelo tamanho do CDV (DxAcm) onde D é o diâmetro e A a altura, corrente I, tempo de exposição $T_{\exp }$ e voxel.

Tabela 3: Produto Kerma no ar-área CRANEX 3D

\section{CRANEX 3D}

\begin{tabular}{ccccc}
\hline $\begin{array}{c}\text { CDV (DxA) } \\
\mathrm{cm}\end{array}$ & $\begin{array}{c}\text { I } \\
\mathrm{mA}\end{array}$ & $\begin{array}{c}\text { Texp } \\
\mathrm{s}\end{array}$ & $\begin{array}{c}\text { Voxel } \\
\mathrm{mm}\end{array}$ & $\begin{array}{c}\mathbf{P}_{\text {KA }} \\
\mathrm{mGy} \cdot \mathrm{cm}^{2}\end{array}$ \\
\hline $6 \times 8$ & 6,3 & 12,6 & 0,2 & $602,3 \pm 1,8$ \\
$6 \times 8$ & 10 & 4,9 & 0,3 & $416,9 \pm 1,7$ \\
$6 \times 8$ & 3,2 & 2,3 & 0,33 & $72,4 \pm 0,4$ \\
$6 \times 4$ & 8 & 6,1 & 0,133 & $430,7 \pm 1,9$ \\
$6 \times 4$ & 10 & 2,3 & 0,2 & $201,3 \pm 0,9$ \\
$6 \times 4$ & 3,2 & 2,3 & 0,21 & $34,6 \pm 0,4$ \\
\hline
\end{tabular}

Nota-se que o menor valor do $\mathrm{P}_{K A}$ para o CRANEX 3D se dá pra o menor CDV aliado com o menor tempo de exposição e menor $\mathrm{mA}$, o maior valor é encontrado para o maior CDV aliado ao maior tempo de exposição e mA, o que era esperado, uma vez que a dose é proporcional à carga do tubo.

A Tabela 4 mostra os valores de $\mathrm{P}_{\mathrm{KA}}$ para o Eagle 3D, onde cada protocolo está descrito pelo tamanho do CDV, corrente I, tempo de exposição $T_{\exp }$ e voxel. Para este equipamento, os dados se apresentam para três resoluções: padrão (STD), alta definição (HD) e ultra alta definição (UHD). 
Tabela 4: Produto Kerma no ar-área Eagle 3D

\begin{tabular}{|c|c|c|c|c|c|c|}
\hline \multicolumn{7}{|c|}{ Eagle 3D } \\
\hline \multirow{4}{*}{$\begin{array}{c}\text { CDV (DxA) } \\
\mathrm{cm}\end{array}$} & \multirow{4}{*}{$\begin{array}{c}\mathrm{I} \\
\mathrm{mA}\end{array}$} & \multirow{4}{*}{$\begin{array}{c}\text { Texp } \\
\text { STD, HD, UHD } \\
(\mathrm{s} ; \mathrm{s} ; \mathrm{s})\end{array}$} & \multirow{4}{*}{$\begin{array}{c}\text { Voxel } \\
\text { STD, HD, UHD } \\
(\mathrm{mm} ; \mathrm{mm} ; \mathrm{mm})\end{array}$} & \multicolumn{3}{|c|}{$\mathbf{P}_{\mathrm{KA}}$} \\
\hline & & & & Res STD & Res HD & Res UHD \\
\hline & & & & mGy & mGy & mGy \\
\hline & & & & $\times \mathrm{cm}^{2}$ & $\times \mathrm{cm}^{2}$ & $\times \mathrm{cm}^{2}$ \\
\hline $5 \times 5$ & 5 & 20,$5 ; 25,5 ; 32$ & 0,$13 ; 0,10 ; 0,08$ & $745,7 \pm 8,6$ & $935,2 \pm 8,3$ & $1172,1 \pm 10,4$ \\
\hline $8 \times 6$ & 5 & 20,$5 ; 25,5 ; 32$ & 0,$20 ; 0,16 ; 0,13$ & $1158,4 \pm 10,4$ & $1450,9 \pm 13,0$ & $1817,0 \pm 16,1$ \\
\hline $8 \times 8$ & 5 & 20,$5 ; 25,5 ; 32$ & 0,$20 ; 0,16 ; 0,13$ & $1370,7 \pm 12,2$ & $1706,7 \pm 1,51$ & $2141,18 \pm 19,1$ \\
\hline $12 \times 8$ & 5 & 20,$5 ; 25,5 ; 32$ & 0,$25 ; 0,20 ; 0,16$ & $1358,5 \pm 12,2$ & $1689,6 \pm 15,3$ & $2121,0 \pm 18,9$ \\
\hline $16 \times 8$ & 5 & 20,$5 ; 25,5 ; 32$ & 0,$40 ; 0,32 ; 0,25$ & $1354,2 \pm 12,1$ & $1673,4 \pm 15,2$ & $2117,8 \pm 18,8$ \\
\hline $16 \times 13$ & 5 & 20,$5 ; 25,5 ; 32$ & 0,$40 ; 0,32 ; 0,25$ & $1354,3 \pm 12,3$ & $1680,5 \pm 15,0$ & $2116,4 \pm 18,8$ \\
\hline $16 \times 18$ & 5 & 20,$5 ; 25,5 ; 32$ & 0,$40 ; 0,32 ; 0,25$ & $1354,7 \pm 12,5$ & $1681,7 \pm 15,0$ & $2117,1 \pm 18,8$ \\
\hline $16 \times 23$ & 5 & 20,$5 ; 25,5 ; 32$ & 0,$40 ; 0,32 ; 0,25$ & $1353,3 \pm 12,1$ & $1684,2 \pm 15,0$ & $2120,5 \pm 18,8$ \\
\hline
\end{tabular}

Observa-se para qualquer resolução configurada no Eagle 3D, que a partir do CDV $8 \times 6$ os valores do $P_{K A}$ tendem a ser manterem constantes com o aumento do CDV, levando-se em consideração que o mAs não varia entre os diferentes CDVs quando uma resolução apenas é utilizada, sendo o maior valor registrado de $2141,18 \mathrm{mGy} \cdot \mathrm{cm}^{2}$.

A Tabela 5 mostra os valores de $P_{K A}$ para o i-CAT Classic, onde cada protocolo está descrito pelo tamanho do CDV, corrente vezes tempo de exposição (mAs) e voxel.

Tabela 5: Produto Kerma no ar-área i-CAT Classic

i-CAT Classic

\begin{tabular}{cccc}
\hline $\begin{array}{c}\text { CDV (DxA) } \\
\mathrm{cm}\end{array}$ & $\begin{array}{c}\mathbf{I} \times \text { Texp } \\
\mathrm{mAs}\end{array}$ & $\begin{array}{c}\text { voxel } \\
\mathrm{mm}\end{array}$ & $\begin{array}{c}\mathbf{P}_{\mathbf{K A}} \\
\mathrm{mGy} \cdot \mathrm{cm}^{2}\end{array}$ \\
\hline $16 \times 6$ & 9,65 & 0,$3 ; 0,4$ & $201,3 \pm 1,0$ \\
$16 \times 6$ & 18,45 & 0,3 & $386,0 \pm 3,6$ \\
$16 \times 6$ & 36,12 & 0,$2 ; 0,25$ & $747,9 \pm 4,1$ \\
$16 \times 8$ & 9,65 & 0,4 & $255,3 \pm 2,5$ \\
$16 \times 8$ & 18,45 & 0,$3 ; 0,4$ & $486,5 \pm 2,5$ \\
$16 \times 8$ & 36,12 & 0,$2 ; 0,25$ & $948,7 \pm 10,2$ \\
$16 \times 13$ & 9,65 & 0,4 & $355,6 \pm 1,8$ \\
$16 \times 13$ & 18,45 & 0,$3 ; 0,4$ & $682,3 \pm 3,3$ \\
$16 \times 13$ & 36,12 & 0,25 & $1322,1 \pm 6,4$ \\
$16 \times 22$ & 36,09 & 0,3 & $1133,0 \pm 5,4$ \\
\hline
\end{tabular}

A faixa de dose em que o i-CAT Classic trabalha está entre 201,3 e $1322 \mathrm{mGy} \cdot \mathrm{cm}^{2}$ com os valores de mAs mínimo e máximo respectivamente. 
A Tabela 6 mostra os valores de $\mathrm{P}_{\mathrm{KA}}$ para o i-CAT FLX, onde cada protocolo está descrito pelo tamanho do CDV, corrente vezes tempo de exposição (mAs) e voxel.

\begin{tabular}{cccc}
\multicolumn{4}{c}{ Tabela 6: Produto Kerma no ar-área i-CAT FLX } \\
\hline \multicolumn{4}{c}{ i-CAT FLX } \\
\hline CDV (DxA) & $\begin{array}{c}\text { I } \times \text { Texp } \\
\text { cm }\end{array}$ & voxel & PAs $_{\text {KA }}$ \\
$\mathrm{mm}$ & $\mathrm{mGy} \cdot \mathrm{cm}^{2}$ \\
\hline $8 \times 8$ & 37,07 & 0,25 & $519,3 \pm 5,4$ \\
$16 \times 6$ & 37,07 & 0,25 & $683,2 \pm 3,8$ \\
$16 \times 8$ & 37,07 & 0,25 & $817,1 \pm 5,6$ \\
$16 \times 13$ & 37,07 & 0,25 & $1234,7 \pm 8,0$ \\
$23 \times 17$ & 37,10 & 0,25 & $970,3 \pm 5,7$ \\
\hline
\end{tabular}

O CDV 23x17 do i-CAT FLX deveria entregar maior dose que o CDV 16x13, o que não acontece.

A Tabela 7 mostra os valores de $\mathrm{P}_{\mathrm{KA}}$ para o OP300, onde cada protocolo está descrito pelo tamanho do CDV, corrente vezes tempo de exposição (mAs), tempo de aquisição( $\left.T_{\text {aq }}\right)$ e resolução.

Tabela 7: Produto Kerma no ar-área OP300

\begin{tabular}{ccccc}
\hline \multicolumn{5}{c}{ OP $\mathbf{3 0 0}$} \\
\hline CDV (DxA) & I & Taq & Res & P KA $_{\text {cm }}$ \\
mAs & $\mathrm{s}$ & & $\mathrm{mGy} \cdot \mathrm{cm}^{2}$ \\
\hline $6 \times 4$ & 10 & 2,3 & STD & $204,8 \pm 1,7$ \\
$6 \times 8$ & 4,9 & 10 & STD & $425,2 \pm 3,5$ \\
$6 \times 4$ & 8 & 6,1 & HI & $428,2 \pm 3,5$ \\
$6 \times 8$ & 6,6 & 13 & HI & $697,1 \pm 5,7$ \\
$6 \times 4$ & 10 & 6,1 & ENDO & $531,4 \pm 4,4$ \\
\hline
\end{tabular}

O OP300 possui um protocolo específico para avaliação endodontica, utilizando o menor CDV, é o segundo maior valor de $\mathrm{P}_{\mathrm{KA}}$ dentre os utilizados.

A Tabela 8 mostra os valores de $\mathrm{P}_{\mathrm{KA}}$ para o Prexion 3D, onde cada protocolo está descrito pelo tamanho do CDV, corrente vezes tempo de exposição (mAs), tempo de aquisição( $\left.\mathrm{T}_{\mathrm{aq}}\right)$ e resolução. 
Tabela 8: Produto Kerma no ar-área PREXION 3D

PREXION 3D

\begin{tabular}{ccccc}
\hline $\begin{array}{c}\text { CDV (DxA) } \\
\mathrm{cm}\end{array}$ & $\begin{array}{c}\text { I } \\
\mathrm{mAs}\end{array}$ & $\begin{array}{c}\text { Taq } \\
\mathrm{s}\end{array}$ & Res & $\begin{array}{c}\mathbf{P}_{\mathrm{KA}} \\
\mathrm{mGy} \cdot \mathrm{cm}^{2}\end{array}$ \\
\hline $5 \times 5$ & 4 & 19 & STD & $1446,5 \pm 12,0$ \\
$5 \times 5$ & 4 & 37 & HI & $2901,6 \pm 24$ \\
$8 \times 8$ & 4 & 19 & STD & $1455,8 \pm 12,0$ \\
$8 \times 8$ & 4 & 37 & HI & $1458,9 \pm 12,3$ \\
\hline
\end{tabular}

Detentor do maior valor de $\mathrm{P}_{\mathrm{KA}}$ entre os tomógrafos investigados, o prexion 3D entrega $2901,6 \mathrm{mGy} \cdot \mathrm{cm}^{2}$ para um CDV de $5 \times 5$.

A Tabela 9 mostra os valores de $\mathrm{P}_{\mathrm{KA}}$ para o PAX-Uni 3D, onde cada protocolo está descrito pelo tamanho do CDV, corrente vezes tempo de exposição (mAs), tempo de aquisição( $\left.T_{\text {aq }}\right)$ e resolução.

Tabela 9: Produto Kerma no ar-área PAX Uni-3d

PAX Uni-3D

\begin{tabular}{ccccc}
\hline $\begin{array}{c}\text { CDV (DxA) } \\
\mathrm{cm}\end{array}$ & $\begin{array}{c}\text { I } \\
\mathrm{mAs}\end{array}$ & $\begin{array}{c}\text { Taq } \\
\mathrm{s}\end{array}$ & Res & $\begin{array}{c}\mathbf{P}_{\text {KA }} \\
\mathrm{mGy} \cdot \mathrm{cm}^{2}\end{array}$ \\
\hline $8 \times 5$ & 6 & 1919 & $\mathrm{STD}$ & $473,4 \pm 4,1$ \\
\hline
\end{tabular}

O PAX Uni-3D avaliado, possuia apenas uma configuração de resolução e tamanho de CDV, o valor $P_{K A}$ medido está dentro da grande faixa observada para os tomógrafos.

A seguir, o Grafico7 apresenta a distribuição em densidade de frequência de todos os valores de $\mathrm{P}_{\mathrm{KA}}$ medidos. 


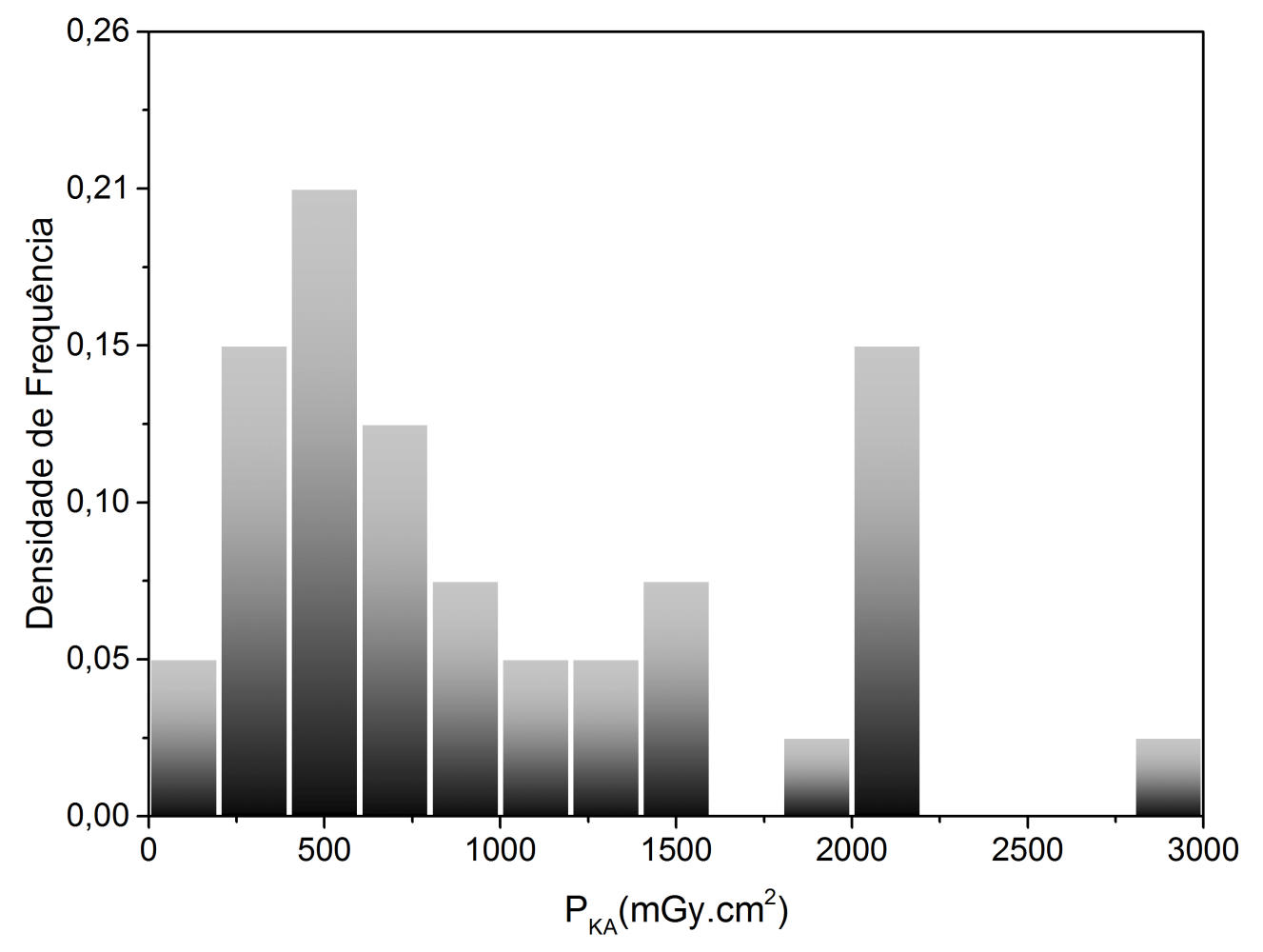

Figura 7: Valores $\mathrm{P}_{\mathrm{KA}}$

Pode-se observar acima, que a maior densidade de valores se encontra entre 400 e $600 \mathrm{mGy} \cdot \mathrm{cm}^{2}$. Abaixo, na tebela 10 , tem-se os valores médios para cada classe em que foi divididos os CDVs.

Tabela 10: Valores médios $\mathrm{P}_{\mathrm{KA}}$ para a divisão em classes de acordo com o tamanho do CDV

\begin{tabular}{cc}
\hline Classes & $\mathbf{P}_{\mathrm{KA}}\left(\mathbf{m G y} \cdot \mathbf{c m}^{\mathbf{2}}\right)$ \\
\hline Pequena & 873,2 \\
Média & 1304,7 \\
Grande & 1407,9 \\
\hline
\end{tabular}

Conclui-se que os valores de $\mathrm{P}_{\mathrm{KA}}$ crescem em média com o aumento do CDV. 


\section{$4.23^{\circ}$ Quartil}

O cálculo do $3^{\circ}$ quartil a partir da distribuição dos valores em ordem crescente do $P_{K A}$ é tomado como o valor de referência para a definição dos NRRs aqui utilizados para a modalidade TCO. A Tabela 11, mostra os valores de níveis de referência calculados para três classes de tamanhos de CDV, e o valor representativo de todos os dados, independente do tamanho do FOV.

Tabela 11: Cálculo dos quartis, representativos dos NRRs para três classes de CDVs, e uma classe global

\begin{tabular}{cccccc}
\hline \multicolumn{6}{c}{ Quartis } \\
\hline \multirow{5}{*}{ Altura CDV (A) } & 30 Quartil & Máximo & Mínimo & Média & Desvio Padrão \\
\cline { 2 - 6 } & 3 $\left.\mathbf{m G} \cdot \mathbf{c m}^{2}\right)$ \\
A $\leq 10 \mathrm{~cm}$ & 1241 & 2901,6 & 34,6 & 873,2 & 722,3 \\
$10<\mathrm{A}<15 \mathrm{~cm}$ & 1521 & 2117,1 & 355,6 & 1304,7 & 659,8 \\
A $\geq 15 \mathrm{~cm}$ & 1408 & 2120,5 & 970,3 & 1407,9 & 508,2 \\
GLOBAL & 1446 & 2901,6 & 34,6 & 980,7 & 726,1 \\
\hline
\end{tabular}

Os dados apresentados acima, tem como maior NRR o valor de $1521 \mathrm{mGy} \cdot \mathrm{cm}^{2}$ para tamanhos de CDVs entre 10 e $15 \mathrm{~cm}$ de altura, e para o NRR global $1446 \mathrm{mGy} \cdot \mathrm{cm}^{2}$ apresentando o maior desvio padrão, como esperado.

\subsection{Resultados Feixes Com Largura Nominal $>\mathbf{4 0} \mathrm{mm}$}

A Tabela 12 mostra os valores do CTDI $_{\mathrm{W}, \mathrm{NT}}$ calculados a partir da Equação 3.6. 
Tabela 12: CTDI i-CAT Classic utilizando metodologia sugerida pela IAEA

\section{i-CAT Classic}

\begin{tabular}{ccc}
\hline Protocolo & CTDI $_{\text {w,ref }}(\mu \mathrm{Gy})$ & CTDI $_{\mathrm{ar}, 100, \text { ref }}(\mu \mathrm{Gy})$ \\
\hline $16 \times 6 \mathrm{~cm}, 40 \mathrm{~s}, 36,12 \mathrm{mAs}$ & $4,02 \pm 0,15$ & $5,16 \pm 0,49$ \\
$16 \times 6 \mathrm{~cm}, 20 \mathrm{~s}, 18,45 \mathrm{mAs}$ & $2,00 \pm 0,10$ & $4,42 \pm 0,11$ \\
$16 \times 6 \mathrm{~cm}, 10 \mathrm{~s}, 9,65 \mathrm{mAs}$ & $1,04 \pm 0,10$ & $1,23 \pm 0,15$ \\
\hline Protocolo & CTDI $_{\mathrm{w}, \mathbf{N T}}(\mu \mathrm{Gy})$ & CTDI $_{\mathrm{ar}, 100, \mathrm{NT}}(\mu \mathrm{Gy})$ \\
\hline $16 \times 8 \mathrm{~cm}, 40 \mathrm{~s}, 36,12 \mathrm{mAs}$ & $4,17 \pm 0,44$ & $5,35 \pm 0,10$ \\
$16 \times 8 \mathrm{~cm}, 20 \mathrm{~s}, 18,45 \mathrm{mAs}$ & $2,22 \pm 0,18$ & $2,68 \pm 0,11$ \\
$16 \times 8 \mathrm{~cm}, 10 \mathrm{~s}, 9,65 \mathrm{mAs}$ & $1,02 \pm 0,16$ & $1,20 \pm 0,11$ \\
$16 \times 13 \mathrm{~cm}, 40 \mathrm{~s}, 36,12 \mathrm{mAs}$ & $4,15 \pm 0,44$ & $5,33 \pm 0,10$ \\
$16 \times 13 \mathrm{~cm}, 20 \mathrm{~s}, 18,45 \mathrm{mAs}$ & $2,24 \pm 0,16$ & $2,71 \pm 0,16$ \\
$16 \times 13 \mathrm{~cm}, 10 \mathrm{~s}, 9,65 \mathrm{mAs}$ & $1,16 \pm 0,16$ & $1,37 \pm 0,06$ \\
$16 \times 22 \mathrm{~cm}, 40 \mathrm{~s}, 36,9 \mathrm{mAs}$ & $3,20 \pm 0,34$ & $4,10 \pm 0,06$ \\
\hline
\end{tabular}

$\mathrm{Na}$ tabela acima, estão representados os valores do CTDI $\mathrm{W}_{\mathrm{N} T}$ calculados para os valores nominais de largura do feixe (NT), onde neste caso, toma-se a altura do CDV sendo o valor nominal NT. A razão entre os índices de dose medidos no ar para a largura de referência e para largura NT em questão representam com quase nenhuma discrepância, a mesma razão, quando calculados no fantoma.

\subsection{Resultados Feixe No $\mathrm{Ar}>60 \mathrm{~mm}$}

A Tabela 13 a seguir, mostra os resultados e uma relação percentual entre o $\mathrm{CTDI}_{300}$ e o $\mathrm{CTDI}_{100}$. 
Tabela 13: Comparação $C T D I_{300}$ em relação ao $C T D I_{100}$ medidos para os equipamentos i-CAT Classic e Prexion 3D

\section{i-CAT Classic}

\begin{tabular}{|c|c|c|c|}
\hline Protocolo & $\begin{array}{c}\text { CTDI }_{100} \\
\mu \mathrm{Gy}\end{array}$ & $\begin{array}{c}\text { CTDI }_{300} \\
\mu \mathrm{Gy}\end{array}$ & $\begin{array}{c}\mathbf{C T D I}_{\mathbf{3 0 0}} / \mathbf{C T D I}_{100} \\
\%\end{array}$ \\
\hline $16 \times 6 \mathrm{~cm}, 40 \mathrm{~s}, 36,12 \mathrm{mAs}$ & $4,02 \pm 0,15$ & $6,76 \pm 0,17$ & 68,2 \\
\hline $16 \times 6 \mathrm{~cm}, 20 \mathrm{~s}, 18,45 \mathrm{mAs}$ & $2,00 \pm 0,10$ & $3,20 \pm 0,11$ & 60,0 \\
\hline $16 \times 6 \mathrm{~cm}, 10 \mathrm{~s}, 9,65 \mathrm{mAs}$ & $1,04 \pm 0,10$ & $1,66 \pm 0,10$ & 59,6 \\
\hline No ar & CTDI $_{100, a r}$ & $\mathrm{CTDI}_{300, \mathrm{ar}}$ & $\mathrm{CTDI}_{300, \mathrm{ar}} / \mathrm{CTDI}_{100, \mathrm{ar}}$ \\
\hline $16 \times 6 \mathrm{~cm}, 40 \mathrm{~s}, 36,12 \mathrm{mAs}$ & $5,15 \pm 0,49$ & $7,16 \pm 0,54$ & 39 \\
\hline $16 \times 6 \mathrm{~cm}, 20 \mathrm{~s}, 18,45 \mathrm{mAs}$ & $2,42 \pm 0,11$ & $3,37 \pm 0,17$ & 39,3 \\
\hline $16 \times 6 \mathrm{~cm}, 10 \mathrm{~s}, 9,65 \mathrm{mAs}$ & $1,23 \pm 0,15$ & $1,71 \pm 0,17$ & 39,0 \\
\hline $16 \times 8 \mathrm{~cm}, 40 \mathrm{~s}, 36,12 \mathrm{mAs}$ & $5,35 \pm 0,10$ & $7,48 \pm 0,16$ & 39,8 \\
\hline $16 \times 8 \mathrm{~cm}, 20 \mathrm{~s}, 18,45 \mathrm{mAs}$ & $2,68 \pm 0,11$ & $3,76 \pm 0,14$ & 40,3 \\
\hline $16 \times 8 \mathrm{~cm}, 10 \mathrm{~s}, 9,65 \mathrm{mAs}$ & $1,20 \pm 0,11$ & $1,67 \pm 0,14$ & 39,2 \\
\hline $16 \times 13 \mathrm{~cm}, 40 \mathrm{~s}, 36,12 \mathrm{mAs}$ & $5,33 \pm 0,10$ & $7,44 \pm 0,13$ & 39,6 \\
\hline $16 \times 13 \mathrm{~cm}, 20 \mathrm{~s}, 18,45 \mathrm{mAs}$ & $2,71 \pm 0,06$ & $3,79 \pm 0,08$ & 39,9 \\
\hline $16 \times 13 \mathrm{~cm}, 10 \mathrm{~s}, 9,65 \mathrm{mAs}$ & $1,37 \pm 0,06$ & $1,92 \pm 0,08$ & 40,1 \\
\hline $16 \times 22 \mathrm{~cm}, 40 \mathrm{~s}, 36,9 \mathrm{mAs}$ & $4,10 \pm 0,06$ & $7,74 \pm 0,10$ & 88,8 \\
\hline \multicolumn{4}{|c|}{ Prexion 3D } \\
\hline & CTDI $_{100, a r}$ & $\mathrm{CTDI}_{300, \mathrm{ar}}$ & $\mathrm{CTDI}_{300, \mathrm{ar}} / \mathrm{CTDI}_{100, \mathrm{ar}}$ \\
\hline & $\mu \mathrm{Gy}$ & $\mu \mathrm{Gy}$ & $\%$ \\
\hline $8 \times 8 \mathrm{STD}, 5 \mathrm{~mA}, 37 \mathrm{~s}$ & $5,62 \pm 0,60$ & $6,76 \pm 0,60$ & 20,2 \\
\hline
\end{tabular}

Pode-se observar da tabela acima, que o $\mathrm{CTDI}_{300}$ chegou a ser $88,8 \%$ maior que o CTDI $_{100}$, e a menor discrepância foi achada para o Prexion 3D com 20,2\% maior. 


\section{Discussão}

Os testes de controle de qualidade, informam as condições de funcionamento dos tomógrafos, e a sua capacidade em fazer um bom exame com qualidade de imagem otimizada. A camada semirredutora explica a qualidade do espectro de raios $X$, é a estimativa do poder de penetração do feixe, quanto maior a CSR, mais penetrante o feixe de raios $X$ será, permite além disso, ter uma noção da filtração total do tubo de raios $X$. Os valores obtidos para CSR representativos de cada TCO, estão listados na Tabela 2, e como esperado para os tomógrafos que trabalham com o maior $\mathrm{kVp}$ que é o caso dos i-CAT FLX e Classic, possuem também as maiores CSRs medidas. A utilização de kVp mais alto, tem influência direta na qualidade de imagem, reduzindo significativamente os artefatos por endurecimento de feixe, artefatos de raia, e espalhamento, assim, os i-CATs quando comparados com os demais, se destacam na qualidade de imagem quando exclusivamente há a presença de vários pinos de implantes na maxila e mandíbula.

O equipamento Prexion 3D possui a menor CSR, considerado como tomógrafo de alta resolução, há a necessidade de se diminuir o ruído quântico aumentando a amostragem dos fótons de raios $X$, mas esse fato poderia ser compensado com o aumento do mAs e da filtração, o que influência na quantidade de fótons e na energia efetiva do feixe. Comparado com o Eagle 3D e Pax-Uni 3D, que trabalham com kVp inferior, e possuem CSRs maiores, atribui-se ao Prexion, possuir fótons de baixa energia em seu espectro de raios $X$ que poderiam ser evitados, reduzindo a dose depositada no paciente.

Infelizmente não há valores de referência para CSR mínima em tomógrafos odontológicos publicados em normas nacionais, no qual podería-se verificar a adequação dos valores achados neste estudo. Os valores mínimos de CSR mais próximos da realidade dos tubos de raios $X$ utilizados pela TCO, são descritos para equipamentos de raios $X$ convencionais com gerador trifásico, spara $k V p$ de 80 e 90 as respectivas CSRs são 2,6 mmAl e 3,0 mmAl, e para $120 \mathrm{kVp}$ o valor da CSR é de 3,9 mmAl (47). 
Analisando agora o rendimento, o Prexion apresentou o maior Kerma no ar por unidade de carga do tubo, contra o OP300 com o menor valor achado. O rendimento é um parâmetro de avaliação geral do desgaste do tubo de raios $X$, desde a uniformidade da superfície do ânodo, desgaste do filamento, deposição de partículas que se soltam do ânodo na janela de saída do feixe. Na instalação do equipamento, o rendimento inicial medido nos testes de aceitação pode ser utilizado como linha de base para os futuros testes.

Os valores de repetitividade do kVp estão todos dentro dos limites aceitáveis, assim, a consistência da voltagem do tubo é mantida entre sucessivas aquisições de imagem. Já para os valores de exatidão do kVp, apenas o i-CAT FLX foi além do limite estabelecido, porém, o valor excedido foi $0,6 \%$ acima do permitido, o que caracteriza estado de atenção, significando observar ao longo do tempo se esse valor excedido vai aumentar a ponto de caracterizar estado de intervenção.

O $\mathrm{P}_{\mathrm{KA}}$ tem sido o índice de dose rotineiramente utilizado para reportar o níveis de radiação em que os pacientes estão expostos em radiografias odontológicas $2 \mathrm{D}$, se tornando a quantidade dosimétrica mais regular fornecida pelos fabricantes. HOYROLD e WALKER (48) analisaram medidas de $P_{K A}$ para 41 unidades TCOs, e propuseram um nível de $250 \mathrm{mGy} \cdot \mathrm{cm}^{2}$ como referência para colocação de um implante na região do primeiro molar superior em um adulto típico. Este valor também foi adotado pelas diretrizes européias como parâmetro de dose alcançável e não como NRR (49).

ENDO e col. (50) encontraram uma faixa de valores $P_{K A}$ entre $126,7 \mathrm{mGy} \cdot \mathrm{cm}^{2}$ e $1476,9 \mathrm{mGy} \cdot \mathrm{cm}^{2}$ medidos para cinco modelos de TCO utilizando dosimetros OSL (optically stimulated luminescent) medindo a dose pontual multiplicada pela área do feixe, onde apenas 3 dos 21 consultórios odontológicos aferidos reportaram níveis de dose abaixo de $250 \mathrm{mGy} \cdot \mathrm{cm}^{2}$ em CDVs pequenos. VASSILEVA E STOYANOV (51) encontraram valores entre $1100 \mathrm{mGy} \cdot \mathrm{cm}^{2}$ e $1850 \mathrm{mGy} \cdot \mathrm{cm}^{2}$ para protocolos adultos, e $540 \mathrm{mGy} \cdot \mathrm{cm}^{2}$ para protocolo pediátrico disponível para o equipamento ILUMA Ultra (IMTEC Imaging, USA).

Os dados $\mathrm{P}_{\mathrm{KA}}$ obtidos para este estudo estão compreendidos em uma faixa entre $34,6 \mathrm{mGy} \cdot \mathrm{cm}^{2}$ para o CRANEX 3D e $2901,6 \mathrm{mGy} \cdot \mathrm{cm}^{2}$ para o PREXION 3D. Essa grande diferença entre estes dois equipamentos se dá pelo fato do PREXION 3D usar uma taxa de amostragem mais alta chegando a 1024 projeções para uma aquisição de alta resolução (HD), corrente maior, tempo de exposição mais longo, feixe contínuo, e alto rendimento. Não só comparado ao CRANEX 3D, o PREXION 3D se destaca como 
TCO que deposita maior dose em relação a todos os tomógrafos descritos neste estudo, justamente pelas características descritas anteriormente.

Uma característica exclusiva foi observada para o Eagle 3D, quando observa-se que para os CDVs maiores que $8 \times 6 \mathrm{~cm}$, os valores de $P_{K A}$ se mantém constantes, ou seja não variam com o tamanho do CDV e sim com a resolução do protocolo utilizado que altera o tempo de exposição. Esse fato pode resultar de duas suposições, onde a primeira é a utilização da mesma configuração de colimação para todos os CDVs maiores que $8 \times 6 \mathrm{~cm}$, e a segunda é a utilização de uma configuração de colimação fixa em que as projeções são adquiridas a partir de uma rotação deslocada em relação ao centro de rotação do tubo de raios $X$ onde o algorítmo de reconstruçao é otimizado para a geometria de aquisição e constrói diferentes tamanhos de CDV.

Os protocolos de aquisição oferecidos pelos tomógrafos, quando utilizados para aquisição de imagem em crianças, deve-se priorizar a redução da dose selecionando os protocolos de menor deposição de dose, que priorizam menor mAs e tempo de aquisição, evitando artefatos de movimento, uma vez que as crianças são duas vezes mais radiossensíveis que um adulto típico. Então, como medida de prevenção e consciência em radioproteção, os parâmetros dosimétricos devem ser revisados e otimizados.

Alguns fabricantes, reportam algum parâmetro dosimétrico tabelado, referente aos níveis de dose para determinado protocolo. Ratificando que esses valores não são medidos no ato da realização do exame, e sim, no momento da instalação durante os testes de aceitação, ou até mesmo antes de sair da fábrica. O monitoramento da dose em tempo real, pode acusar possíveis irregularidades de funcionamento como variações na taxa de exposição, valor do $k \mathrm{~V}$, e queda do rendimento, além de configurar um contexto de segurança em controle de qualidade e radioproteção ao paciente. Dos equipamentos utilizados neste estudo, segue os que apresentam alguma grandeza dosimétrica: o i-CAT Classic apresenta valores de dose medidas no detector (Dose no Detector) para tempos de aquisição de 10, 20, 40s, e apresenta o CTDI apenas para aquisições de $40 \mathrm{~s}$; já para o i-CAT FLX que é mais moderno, reporta va-

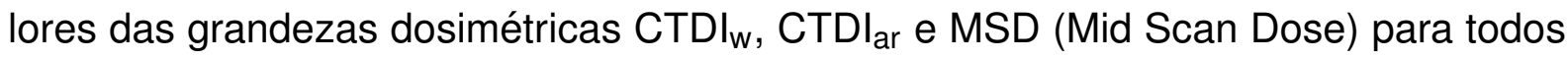
os protocolos disponíveis neste modelo; para o modelo PREXION 3D também é fornecido valores do CTDI $\mathrm{W}_{\mathrm{W}}$ para todos os protocolos; OP300 fornece valores de referência em $P_{K A}$, juntamente com o CRANEX 3D; e os modelos PaX-Uni 3D e Eagle 3D não forneceram nenhuma grandeza dosimétrica para referência. 
A densidade de frequência na Figura 7 é maior para valores de $P_{K A}=500 \mathrm{mGy} \cdot \mathrm{cm}^{2}$, isso indica, que a maior quantidade de protocolos avaliados, entregam em média $500 \mathrm{mGy} \cdot \mathrm{cm}^{2}$. A média de valores para as classes de CDV pequena média e grande foram $873,2 \mathrm{mGy} \cdot \mathrm{cm}^{2}, 1304,7 \mathrm{mGy} \cdot \mathrm{cm}^{2}$ e $1407,9 \mathrm{mGy} \cdot \mathrm{cm}^{2}$ respectivamente mostrados na Tabela 10.

De maneira geral, o $P_{K A}$ é uma grandeza sensível à variação do tamanho do CDV, $\mathrm{mAs}, \mathrm{kV} \mathrm{p}(50)$, e se adequadamente aferido, abrange toda a radiação compreendida no feixe primário independente da geometria de colimação e rotação parcial ou completa, ou seja, toda a quantidade de radiação produzida é medida não havendo a subestimação dos níveis de exposição. Porém, não leva em conta qualquer geometria específica de aquisição (37), como a forma do volume de aquisição definido pelo tamanho do CDV, isso indica que é possível obter valores iguais para protocolos de exposições diferentes tendo todos os parâmetros de exposições diferentes, como exemplo deste fato pode-se confrontar valores muito próximos a partir dos dados deste estudo, tendo i-CAT Classic com CDV $(16 \times 13 \mathrm{~cm})$, mAs $(18,45)$, voxel $(0,3 ; 0,4 \mathrm{~mm})$ com valor $P_{K A}=682,3 \mathrm{mGy} \cdot \mathrm{cm}^{2}$ e i-CAT FLX com CDV (16X6 cm), mAs $(37,07)$, voxel $(0,25 \mathrm{~mm})$ com valor $P_{K A}=683,2 \mathrm{mGy} \cdot \mathrm{cm}^{2}$. LUDLOW (46) confrontou $P_{K A}$ com dose efetiva, onde utilizou um CDV pequeno posicionado em diferentes locais como maxila anterior e posterior, e mandíbula anterior e posterior, e observou uma mudança de até três vezes na dose efetiva, a despeito de nenhuma mudança no valor de $P_{K A}$. PAUWELS e col. (37) concluiu que não é possível ligar o $P_{K A}$ aos valores de dose efetiva do paciente em termos gerais, uma vez que todos os fatores de imagem determinam a distribuição da dose através do paciente. Além disso, o $P_{K A}$ também não leva em consideração a distribuição de dose no plano axial.

$O \mathrm{P}_{\mathrm{KA}}$ fornece uma estimativa da saída do tubo dependente da dose e do tamanho do campo. $O$ índice de dose par TCO, deve ser capaz de cobrir com grande eficácia as diferenças no tamanho do CDV, parâmetros de exposição, e rotações completas e parciais, e aínda ter sensibilidade para distribuições de dose longitudinal e axial (37). Fatores de conversão de dose entre $\mathrm{P}_{\mathrm{KA}}$ e dose efetiva tem sido derivados para radiografias intra-oral, panorâmica e cefalometria (52-55). Esses fatores de conversão quando aplicados à tomografia em geral são complicados, pois o tamanho do campo irradiado, e os fatores de posicionamento e irradiações parciais do tecido ou orgão, devem ser levados em conta, o que ocasiona um complexa interpretação da dose efetiva (56), além da variação dos parâmetros de exposição entre diferentes equipamentos, e diferenças anatômicas entre os indivíduos que adicionam incertezas nesse contexto 
$(35,55)$. O $P_{K A}$ pode ser utilizado como parâmetro dosimetrico para derivação da dose efetiva, porém os fatores de conversão para a dose efetiva, devem ser avaliados no momento da instalação do equipamento pelo próprio fornecedor, onde para cada equipamento, os fatores de conversão seriam característicos e a comparação da dose entre tomógrafos levariam em consideração as características próprias de cada equipamento.

Em 1996 a IAEA (57) propôs níveis de orientação para dose e redução de dose em procedimentos radiológicos, e no mesmo ano a ICRP (International Commission on Radilogical Protection) (58) recomendou o uso dos NRRs aplicados aos pacientes. A ICRP 103 (59) recomenda que os NRRs devem ser definidos por país ou região específica, e revisados periódicamente. O NRR deve ser uma grandeza fácil de medir e utilizada para otimizar precedimentos diagnósticos, pois indicam níveis quantitativos que informam se a dose no paciente é alta ou baixa. Uma vez que o níveis de dose aferidos excederem o NRR, deve-se revisar os equipamentos para adequar a otimização da radioproteção e redução dos níveis de dose. Usualmente representam a dose absorvida no ar ou tecido equivalente na superfície de um objeto simulador (26).

HAN e col. (26) encontraram um o valor de NRR em TCO para um CDV de $16 \times 18 \mathrm{~cm} 3203 \mathrm{mGy} \cdot \mathrm{cm}^{2}$, e o efeito do tamanho do CDV com a dose foi maior que do mAs. OLIVEIRA e col. (39) também verificou uma variação da dose com o tamanho do CDV, além de encontrar uma faixa de valores para o $P_{K A}$ entre $360,1 \mathrm{mGy} \cdot \mathrm{cm}^{2}$ e $1031,2 \mathrm{mGy} \cdot \mathrm{cm}^{2}$.

Os valores calculados para os NRRs a partir do $3^{\circ}$ quartil neste estudo, mostrados na Tabela 11, estão divididos em três classes de tamanho de CDV, onde para campos pequenos, médios e grandes os valores são $1241 \mathrm{mGy} \cdot \mathrm{cm}^{2}, 1521 \mathrm{mGy} \cdot \mathrm{cm}^{2}$ e $1408 \mathrm{mGy} \cdot \mathrm{cm}^{2}$ respectivamente, e $1446 \mathrm{mGy} \cdot \mathrm{cm}^{2}$ é o valor global. Observa-se que o valor para CDV pequeno chega a ser quase cinco vezes o valor apresentado por HOYROLD e WALKER (48) de $250 \mathrm{mGy} \cdot \mathrm{cm}^{2}$, essa grande diferença pode ser atribuida aos diferentes equipamentos e protocolos utilizados para se derivar os níveis de referência. Para o valor representando CDV grande, compara-se com o NRR reportado por HAN e col. $3203 \mathrm{mGy} \cdot \mathrm{cm}^{2}$, contra $1408 \mathrm{mGy} \cdot \mathrm{cm}^{2}$ deste estudo. Existe uma vasta faixa de dose medida em diversos trabalhos, uma vez, que levar em consideração a metodologia utilizada, os parâmetros de exposição, variação entre os medidores $P_{K A}$, seria 
muito trabalhoso, assim, a melhor forma de determinar a grandeza dosimétrica de referência, é fazer o levantamento regional, e aplicar a determida parte da população.

A metologia proposta pelo protocolo de dosimetria da IAEA (2011)(3), calcula o CTDI no objeto simulador para qualquer largura de feixe $\mathrm{N} \cdot \mathrm{T}$, a partir de valores de referência no ar e no objeto simulador. Observando de maneira geral os dados na Tabela 12, é visível o fato do $\mathrm{CTDI}_{\mathrm{ar}, 100 \text {,ref }}$ ser maior que o $\mathrm{CTDI}_{\mathrm{w} \text {,ref, }}$, isso pode ser justificado por este último ser medido com objeto simulador em posição, que é responsável pela atenuação do feixe de raios $X$ entre o detector e a fonte. Os protocolos disponíveis para o equipamento i-CAT Classic, possuem três configurações de mAs, então, para cada configuração foi aplicado a equação 3.6.

Uma limitação encontrada na aplicação deste método foi para a largura de referência $\mathrm{N} \cdot \mathrm{T}$ ter que ser menor ou igual a $2 \mathrm{~cm}$ (3), largura que não se encontra em nenhum dos TCOs disponíveis no mercado, sendo a largura mínima nominal disponível de $5 \mathrm{~cm}$. Assim, o estudo realizado considerou para largura mínima de referência, a menor largura de feixe disponível no equipamento utilizado, para iCAT e Prexion são de $6 \mathrm{~cm}$ e $5 \mathrm{~cm}$ respectivamente. A tabela 12 estão os valores calculados a partir dos valores de referência utilizando a equação 3.6 na página 48. A razão entre

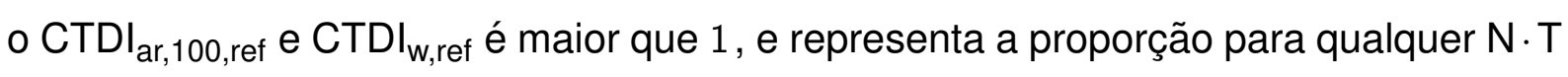
desejado, indicando que este tipo de procedimento funciona de maneira aceitável, e pode ser aplicado como uma ferramenta para tornar prática a dosimetria em testes de controle de qualidade.

Afim de se ter uma idéia mais concreta em relação aos comprimentos de integração dos perfis de dose, comparou-se os valores de dose obtidos a partir dos índices de dose CDTI com comprimentos de integração de 100 mm e 300 mm, com o objetivo de verificar a discrepância percentual entre eles, fato que poderá influenciar os valores de dose efetiva, quando utilizados os fatores de conversão (60).

Tendo-se a noção das diferenças entre os valores, pode-se dizer que o índice padrão, mundialmente uilizado para a estimativa de dose em tomógrafos computadorizados o $\mathrm{CTDI}_{100}$, subestima muito a dose depositada no eixo central, onde uma comparação entre CTDI 100 e $\mathrm{CTDI}_{300}$, reportou que o $\mathrm{CTDI}_{300}$ é em média $49 \%$ maior em relação ao $C T D I_{100}$, isso leva a concluir que a integral do perfil de dose contabilizada para um comprimento de $300 \mathrm{~mm}$ não só cobre completamente as dimensões de feixe para TCO que atualmente estão no mercado, mas também abrange de maneira mais eficiente a radiação espalhada a partir do feixe primário incidente no objeto 
simulador $(60,61)$. Observe que a partir da definição do CTDI, a integral de dose é unidimensional, e leva em consideraçao radiação primária e secundária e a partir dos valores obtidos neste experimento, reportam apenas estimativas da quantidade de radiação que o equipamento em questão possa entregar ao paciente, o que incita que o CTDI 300 apresenta um valor da estimativa de dose mais completa para feixes largos. Os valores de dose medidos imediatamente superior e inferior em relação a posição central do feixe, depositam dose na calota cranial superior, e pescoço, onde está localizada a tireóide, um dos orgãos radiossensíveis presentes no corpo humano. O CTDI não leva em consideração nenhum fator de risco ou radiossensibilidade do tecido irradiado.

Infelizmente, esse protocolo de medida não pode ser realizado para todos os tomógrafos estudados, pois algumas máquinas possuem sistema de posicionamento e imobilização para aquisição da imagem com o paciente em pé, assim, os aparatos de imobilização não permitem o posicionamento do objeto simulador no feixe de radiação.

Discussões entre a utilização ou não do CTDI ou outra grandeza dosimétrica tem sido realizada (62-64). A principal limitação do CTDI é o seu comprimento de integração de $100 \mathrm{~mm}$, muito curto para englobar toda a calda de radiação espalhada gerada por uma unidade TCO; uma outra limitação é a diferença do CTDI e o DLP (Dose Length Product), pois o CTDI é o DLP dividido pela espessura do feixe . Por exemplo, se um protocolo com altura de $13 \mathrm{~cm}$ for usado, a altura escaneada é maior que o comprimento da câmara, ou seja o feixe primário e toda a cauda de espalhamento não serão contabilizados, e dividindo o DLP pela espessura do feixe, obtém-se um descritor de dose completamente errado. MORI e col. (63) e LOUBELE e col. (65) citam que a utilização de objetos simuladores mais longos, são impossíveis em aplicações dentomaxillofaciais. LOUBELE e col. (65) conclui que a utilização do DLP é o mais adequado, uma vez que a dose aferida pelos $10 \mathrm{~cm}$ da câmara de ionização, não depende da espessura do feixe mesmo sendo maior que $10 \mathrm{~cm}$.

Há uma vasta quantidade de TCOs disponíveis no mercado, e uma variabilidade enorme é percebida em termos dos fatores de exposição. A métrica tipicamente utilizada para avalição do risco é a dose efetiva (35, 66-68), calculada pela equação 1.18 e definida pela ICRP. Geralmente é medida em um objeto simulador antropomórfico para um adulto típico, que fornece então uma estimativa do risco global para efeitos de câncer induzido a partir da exposição a radiação. Porém, possui limitações e 
não é adequada para estimar riscos (69), o principal problema, é que a dose efetiva é variável com o tamanho e idade dos pacientes, e isso é de importante relevância no contexto da tomografia odontológica, pois, crianças e jovens frequentemente são submetidos a precedimentos tomográficos para pesquisa de defeitos dentomaxilofaciais, tratamentos ortodônticos ou traumas. Trabalhos publicados mostraram que a dose efetiva a partir da TCO chega a ser entre 5 e 80 vezes maiores comparadas a radiografia panorâmica, e 1 a 23\% comparados com a TC convencional (51). ABDELKARIM (70) conclui que a razão risco-benefício para o uso da TCO é favorável, porém é impossível avaliar os efeitos estocásticos a longo prazo porque existem vários fatores carcinogênicos presentes na vida humana. 


\section{Conclusões}

É indispensável os testes de controle de qualidade no contexto de radioproteção e qualidade de imagem. É dever do responsável técnico do serviço, sempre estar em contato com os procedimentos radiológicos, a fim de gerenciar e orientar os técnicos sobre possíveis ações irregulares e atitudes corretivas a serem tomadas. A clínica odontológica não deve realizar procedimentos radiológicos sem a devida justificativa para utilização. O dentista deve recorrer a técnicas com maior utilização de dose, quando já considerados imagens anteriores com a mesma finalidade, porém com informações inconclusivas. Em procedimentos aplicados a crianças, deve-se analisar criteriosamente a finalidade do pedido e sua justificativa, pesar com maior seriedade a indicação de TCO para pesquisa patológica, e dentro deste contexto selecionar corretamente o protocolo de aquisição, considerando a redução da dose e evitando artefatos por movimento, o que acarretaria em uma repetição do exame, e até mesmo considerar a redução da resolução ou qualidade de imagem, lógicamente ponderada pelo tipo de patologia estudada.

O $\mathrm{P}_{\mathrm{KA}}$ se mostrou um parâmetro bastante eficiente na dosimetria para TCO, mesmo com suas limitações de não considerar a geometria do feixe e distribuição de dose axial, a ação de se medir toda a radiação que sai da fonte, mesmo que o paciente não seja exposto completamente por todo o feixe, indica qual o nível máximo de dose que pode diretamente insidir sobre o paciente, e a partir dessa conclusão, a definição do NRR para odontologia se faz efetiva, já que esta grandeza leva em consideração variações no parâmetro de exposição, queda do rendimento e a efetividade dos colimadores em delimitar o campo de radiação.

Utilizar comprimentos de integração maiores para instalações que usam o CTDI ou $\mathrm{CTDI}_{\mathrm{w}}$ deve ser de extrema urgência considerados para campos que excedem $60 \mathrm{~mm}$ de espessura, evitando a subestimação da dose. Ou utilizar o DLP como parâmetro sensível às variações na estabilidade dos fatores técnicos de máquina. 
Quando fala-se em radiação, independente da taxa ou intensidade, deve-se mudar a postura e consciência, e aplicar com grande seriedade a proteção dos indivíduos ocupacional e medicamente expostos, uma vez que o danos causados pela radiação ocorrem a níveis celulares e são cumulativos, isso representa que quanto maior a dose, maior a probabilidade de manifestação dos efeitos estocásticos. 


\section{Referências}

1 BUSHBERG, J. T.; BOONE, J. M. The essential physics of medical imaging. [S.I.]: Lippincott Williams \& Wilkins, 2011.

2 ATTIX, F. H. Introduction to radiological physics and radiation dosimetry. [S.I.]: John Wiley \& Sons, 2004.

3 IAEA. Status of Computed Tomography Dosimetry for Wide Cone Beam CT Scanners. [S.I.], 2011 a.

4 FILHO, L. C. et al. Um novo método para avaliar as inclinações dentárias utilizando a tomografia computadorizada. Revista Dental Press de Ortodontia e Ortopedia Facial, SciELO Brasil, v. 10, n. 5, p. 23-9, 2005.

5 GARIB, D. G. et al. Tomografia computadorizada de feixe cônico (Cone beam): entendendo este novo método de diagnóstico por imagem com promissora aplicabilidade na Ortodontia. Revista Dental Press de Ortodontia e Ortopedia Facial, SciELO Brasil, v. 12, n. 2, p. 139-56, 2007.

6 RODRIGUES, A. F.; VITRAL, R. W. F. Aplicações da tomografia computadorizada na odontologia. Pesquisa Brasileira em Odontopediatria Clínica Integrada, v. 7, p. 317-24, 2007.

7 PORTARIA, M. 453 Diretrizes De Proteção Radiológica Em Radiodiagnóstico Médico E Odontológico. Diário Oficial da União, Brasília, v. 2, 1998.

8 BONNELL, J. Icru report 19. Radiation Quantities and Units. British journal of industrial medicine, BMJ Group, v. 29, n. 4, p. 464, 1972.

9 PERNICKA, F.; MCLEAN, I. Dosimetry in diagnostic radiology: an international code of practice. International Atomic Energy Agency, 2007.

10 SHOPE, T. B.; GAGNE, R. M.; JOHNSON, G. C. A method for describing the doses delivered by transmission x-ray computed tomography. Medical Physics, Wiley Online Library, v. 8, n. 4, p. 488-495, 1981.

11 MCCOLLOUGH, C. et al. The measurement, reporting, and management of radiation dose in CT. Report of AAPM Task Group, v. 23, p. 1-28, 2008.

12 LEITZ, W.; AXELSSON, B.; SZENDRÖ, G. Computed tomography dose assessment - a practical approach. Radiation Protection Dosimetry, NTP, v. 57, n. 1-4, p. 377-380, 1995.

13 IAEA. Quality Assurance Programme for Computed Tomography: Diagnostic and Therapy Applications. [S.I.], $2011 \mathrm{~b}$. 
14 DIXON, R. et al. Comprehensive methodology for the evaluation of radiation dose in x-ray computed tomography. Report of AAPM Task Group, v. 111, p. 20740-3846, 2010.

15 ICRU. Quantities and Units in Radiation Protection Dosimetry. [S.I.], 1993.

16 ICRP. Recommendations of the International Commission on Radiological Protection. [S.I.], 1991.

17 HOBBIE, R.; ROTH, B. J. Intermediate physics for medicine and biology. [S.I.]: Springer Science \& Business Media, 2007.

18 KALENDER, W. A. Computed tomography: fundamentals, system technology, image quality, applications. [S.I.]: John Wiley \& Sons, 2011.

19 HENDEE, W. R.; RITENOUR, E. R. Medical imaging physics. [S.I.]: John Wiley \& Sons, 2003.

20 KILJUNEN, T. et al. Dental cone beam CT: A review. Physica Medica, Elsevier, v. 31, n. 8, p. 844-860, 2015.

21 ROBERTS, J. et al. Effective dose from cone beam CT examinations in dentistry. The British Journal of Radiology, British Institute of Radiology, 2014.

22 MOUNTFORD, P.; TEMPERTON, D. Recommendations of the international commission on radiological protection (ICRP) 1990. European Journal of Nuclear Medicine and Molecular Imaging, Springer, v. 19, n. 2, p. 77-79, 1992.

23 STREFFER, C. The ICRP 2007 recommendations. Radiation Protection Dosimetry, NTP, v. 127, n. 1-4, p. 2-7, 2007.

24 TORRES, M. G. G. et al. Evaluation of referential dosages obtained by Cone-Beam Computed Tomography examinations acquired with different voxel sizes. Dental Press Journal of Orthodontics, SciELO Brasil, v. 15, n. 5, p. 42-43, 2010.

25 HELMROT, E.; THILANDER-KLANG, A. Methods for monitoring patient dose in dental radiology. Radiation Protection Dosimetry, NTP, p. ncq095, 2010.

26 HAN, S. et al. Dose area product measurement for diagnostic reference levels and analysis of patient dose in dental radiography. Radiation Protection Dosimetry, NTP, p. ncr439, 2011.

27 PAUWELS, R. et al. Effective dose range for dental cone beam computed tomography scanners. European Journal of Radiology, Elsevier, v. 81, n. 2, p. 267-271, 2012.

28 BATISTA, W.; NAVARRO, M.; MAIA, A. Effective doses in panoramic images from conventional and CBCT equipment. Radiation Protection Dosimetry, NTP, v. 151, n. 1, p. 67-75, 2012.

$29 \mathrm{LI}, \mathrm{G}$. Patient radiation dose and protection from cone-beam computed tomography. Imaging Science in Dentistry, v. 43, n. 2, p. 63-69, 2013. 
30 ARAKI, K. et al. Dose indices in dental cone beam CT and correlation with dose-area product. Dentomaxillofacial Radiology, The British Institute of Radiology. 48-50 St John Street, London EC1M 4DG, UK, v. 42, n. 5, p. 20120362, 2013.

31 ANDRADE, M. E. et al. Dosimetric evaluation of dental implant planning examinations with cone-beam computed tomography. Radiation Protection Dosimetry, NTP, p. nct211, 2013.

32 LUDLOW, J. B.; WALKER, C. Assessment of phantom dosimetry and image quality of i-CAT FLX cone-beam computed tomography. American Journal of Orthodontics and Dentofacial Orthopedics, Elsevier, v. 144, n. 6, p. 802-817, 2013.

33 BATISTA, W.; NAVARRO, M. T.; MAIA, A. Development of a phantom and a methodology for evaluation of depth kerma and kerma index for dental cone beam computed tomography. Radiation Protection Dosimetry, NTP, p. nct174, 2013.

34 KIM, D.-S.; RASHSUREN, O.; KIM, E.-K. Conversion coefficients for the estimation of effective dose in cone-beam CT. Imaging Science in Dentistry, v. 44, n. 1, p. 21-29, 2014.

35 PAUWELS, R. et al. Estimating cancer risk from dental cone-beam CT exposures based on skin dosimetry. Physics in Medicine and Biology, IOP Publishing, v. 59, n. 14, p. 3877, 2014.

36 BEIR, V. et al. Health risks from exposure to low levels of ionizing radiation. BEIR VII phase, v. 2, p. 65-79, 2006.

37 PAUWELS, R. et al. Dose distribution for dental cone beam CT and its implication for defining a dose index. Dentomaxillofacial Radiology, The British Institute of Radiology. 131-151 Great Titchfield Street, London W1W 5BB, 2014.

38 SUOMALAINEN, A. et al. Dosimetry and image quality of four dental cone beam computed tomography scanners compared with multislice computed tomography scanners. Dentomaxillofacial Radiology, British Institute of Radiology, 2014.

39 OLIVEIRA, M. V. L. de et al. Air kerma area product in cone beam computed tomography. Revista de Ciências Médicas e Biológicas, v. 13, n. 3, p. 309-312, 2015.

40 SIGNORELLI, L. et al. Radiation dose of cone-beam computed tomography compared to conventional radiographs in orthodontics. Journal of Orofacial Orthopedics/Fortschritte der Kieferorthopädie, Springer, v. 77, n. 1, p. 9-15, 2016.

41 BAPTISTA, M. et al. Entrance Surface Dose distribution and organ dose assessment for Cone-Beam Computed Tomography using measurements and Monte Carlo simulations with voxel phantoms. Radiation Physics and Chemistry, Elsevier, 2017.

42 POPPE, B. et al. Radiation exposure and dose evaluation in intraoral dental radiology. Radiation Protection Dosimetry, NTP, v. 123, n. 2, p. 262-267, 2007.

43 POPPE, B. et al. Dose-area product measurements in panoramic dental radiology. Radiation Protection Dosimetry, NTP, v. 123, n. 1, p. 131-134, 2007. 
44 LOOE, $\mathrm{H}$. et al. Radiation exposure to children in intraoral dental radiology. Radiation Protection Dosimetry, NTP, v. 121, n. 4, p. 461-465, 2006.

45 TIERRIS, C. E. et al. Dose area product reference levels in dental panoramic radiology. Radiation Protection Dosimetry, NTP, v. 111, n. 3, p. 283-287, 2004.

46 LUDLOW, J. B. Dose and risk in dental diagnostic imaging: with emphasis on dosimetry of CBCT. Korean Journal of Oral and Maxillofacial Radiology, v. 39, n. 4, p. 175-84, 2009.

47 BARCELLOS, P. Radiodiagnóstico médico: desempenho de equipamentos e segurança. [S.I.]: Ministério da Saúde, 2005.

48 HOLROYD, J.; WALKER, A. Recommendations for the design of X-ray facilities and the quality assurance of dental cone beam CT (computed tomography) systems. Health Protection Agency. Available from: http://www. hpa. org. uk/webc/HPAwebFile/HPAweb_C/1267551245480, 2010.

49 PROTECTION, R. No 172. Evidence based guidelines on cone beam CT for dental and maxillofacial radiology [Internet]. Luxemburg: European commission; 2012 [cited 2012 September 30].

50 ENDO, A. et al. A preliminary study to determine the diagnostic reference level using dose-area product for limited-area cone beam CT. Dentomaxillofacial Radiology, The British Institute of Radiology. 48-50 St John Street, London EC1M 4DG, UK, v. 42, n. 4, p. 20120097, 2013.

51 VASSILEVA, J.; STOYANOV, D. Quality control and patient dosimetry in dental cone beam ct. Radiation Protection Dosimetry, NTP, v. 139, n. 1-3, p. 310-312, 2010.

52 LOOE, H. et al. Dose-area product measurements and determination of conversion coefficients for the estimation of effective dose in dental lateral cephalometric radiology. Radiation Protection Dosimetry, NTP, v. 124, n. 2, p. 181-186, 2007.

53 LOOE, $\mathrm{H}$. et al. Conversion coefficients for the estimation of effective doses in intraoral and panoramic dental radiology from dose-area product values. Radiation Protection Dosimetry, NTP, v. 131, n. 3, p. 365-373, 2008.

54 HELMROT, E.; CARLSSON, G. A. Measurement of radiation dose in dental radiology. Radiation Protection Dosimetry, NTP, v. 114, n. 1-3, p. 168-171, 2005.

55 MAURO, R. A. P.; SOUZA, D. M. de; COSTA, A. M. da. Produto kerma no ar-área e dose efetiva em radiodiagnóstico odontológico. Revista Brasileira de Física Médica, v. 10, n. 1, p. 22-26, 2017.

56 WISE, K. et al. Sensitivity of coefficients for converting entrance surface dose and kerma-area product to effective dose and energy imparted to the patient. Physics in Medicine and Biology, IOP Publishing, v. 44, n. 8, p. 1937, 1999.

57 PROTECTION, I. C. on R. ICRP Publication 73: Radiological Protection and Safety in Medicine. [S.I.]: Elsevier Health Sciences, 1996. 
58 ORGANIZATION, W. H. et al. International basic safety standards for protecting against ionizing radiation and for the safety of radiation sources. 1996.

59 PROTECTION, R. Icrp publication 103. Ann. ICRP, v. 37, n. 2.4, p. 2, 2007.

$60 \mathrm{KIM}, \mathrm{S}$. et al. Computed tomography dose index and dose length product for cone-beam CT: Monte Carlo simulations of a commercial system. Journal of Applied Clinical Medical Physics, Wiley Online Library, v. 12, n. 2, p. 84-95, 2011.

61 GELEIJNS, J. et al. Computed tomography dose assessment for a $160 \mathrm{~mm}$ wide, 320 detector row, cone beam CT scanner. Physics in Medicine and Biology, IOP Publishing, v. 54, n. 10, p. 3141, 2009.

62 DIXON, R. L. Restructuring CT dosimetry-a realistic strategy for the future requiem for the pencil chamber. Medical Physics, Wiley Online Library, v. 33, n. 10, p. 3973-3976, 2006.

$63 \mathrm{MORI}$, S. et al. Enlarged longitudinal dose profiles in cone-beam CT and the need for modified dosimetry. Medical Physics, Wiley Online Library, v. 32, n. 4, p. 1061-1069, 2005.

64 MCCOLLOUGH, C. H. It is time to retire the computed tomography dose index (CTDI) for CT quality assurance and dose optimization. Against the proposition. Medical Physics, v. 33, n. 5, p. 1190-1191, 2006.

65 LOUBELE, M. et al. Image quality vs radiation dose of four cone beam computed tomography scanners. Dentomaxillofacial Radiology, British Institute of Radiology, 2014.

66 EVANS, C. A. et al. Clinical recommendations regarding use of cone beam computed tomography in orthodontics. Position statement by the American Academy of Oral and Maxillofacial Radiology. ORAL SURGERY ORAL MEDICINE ORAL PATHOLOGY ORAL RADIOLOGY, ELSEVIER SCIENCE INC 360 PARK AVE SOUTH, NEW YORK, NY 10010-1710 USA, v. 116, n. 2, p. 238-257, 2013.

67 BROOKS, S. L. Cbct dosimetry: orthodontic considerations. In: ELSEVIER. Seminars in Orthodontics. [S.I.], 2009. v. 15, n. 1, p. 14-18.

68 LUDLOW, J. et al. Effective dose of dental CBCT - a meta analysis of published data and additional data for nine CBCT units. Dentomaxillofacial Radiology, The British Institute of Radiology., v. 44, n. 1, p. 20140197, 2014.

69 BRENNER, D. Effective dose: a flawed concept that could and should be replaced. The British Journal of Radiology, British Institute of Radiology, 2014.

70 ABDELKARIM, A. Myths and facts of cone beam computed tomography in orthodontics. Journal of the World Federation of Orthodontists, Elsevier, v. 1, n. 1, p. e3-e8, 2012. 